Article

\title{
A New Method for the Quantitative Assessment of Sustainable Development Goals (SDGs) and a Case Study on Central Asia
}

\author{
Yizhong Huan ${ }^{1,2}$, Haitao $\mathrm{Li}^{1, *(\mathbb{D})}$ and Tao Liang ${ }^{1,2}$ \\ 1 Key Laboratory of Land Surface Pattern and Simulation, Institute of Geographic Sciences and Natural \\ Resources Research, Chinese Academy of Sciences, Beijing 100101, China \\ 2 University of Chinese Academy of Sciences, Beijing 10049, China \\ * Correspondence: liht@igsnrr.ac.cn; Tel.: +86-10-64888996
}

Received: 5 May 2019; Accepted: 23 June 2019; Published: 26 June 2019

check for updates

\begin{abstract}
Regarding the sustainable development goals (SDGs) formulated by the United Nations (UN), how to effectively measure, assess and compare the progress and trends of these SDGs in different countries was the problem we wanted to address. Based on past quantitative assessments, this paper proposed a new methodological framework for SDG assessment and analysis, and used two typical Central Asian countries, Kazakhstan and Kyrgyzstan, as the sample area to test the framework. Our study chose 209 indicators and indicator sets, including 429 specific indicators and collected relevant indicator data for the two countries from 2000 to 2017, then proposed a new direction for the unification of indicator data as well as methods for normalization. Afterward, the scores of each goal and SDG performance were calculated. This analysis was also done innovatively using the Chow Test to conduct further analysis of the SDG performance. According to the assessment, over those 18 years, Kyrgyzstan's SDGs had been performing poorly, especially the economic SDGs, while the performance of Kazakhstan's SDGs had remained in constant fluctuation. It could be said that the SDG performance in Central Asia as a whole was not very optimistic. It required the devotion of greater efforts in the gathering of different types of indicator data because there were still gaps in data collection between countries as well as the missing of time-series data, which could challenge the indicator selection and further restrict the follow-up assessment and analysis. The assessment framework presented in this paper can be applied for assessing the long-term performance of national SDGs of different countries, helping analyze the internal relationship dynamic among and within countries, underscoring specific issues of sustainable development, assessing policy and selecting development models and directions.
\end{abstract}

Keywords: sustainable development goals; sustainable development; sustainability; sustainable indicators; SDGs assessment; SDGs performance; Kazakhstan; Kyrgyzstan

\section{Introduction}

Over the past 20 years, there has been a substantial increase in methods and indices for measuring sustainable development. Many scholars and research institutions have been adopting a series of sustainable development indicators and composite indices in different countries and regions to track the progress made in terms of sustainable development [1-6]. From 2015 to 2018, the United Nations (UN) published, implemented, and improved the global SDG framework, which currently includes 244 indicators corresponding to 17 goals and 169 targets reinforcing the growing importance of these indicators [7]. Although SDGs are complex and wide-ranging, the coordination of viewpoints and explanations of sustainable development and reaching international agreement over a set of SDIs 
represent a critical initial step [8]. The comprehensive indicator framework can transform SDGs and their targets into a management tool and help countries formulate and implement strategies and distribute resources accordingly, as well as provide the basis for research reports on evaluating the progress of sustainable development [9].

Indicator-based assessment is the process in which information on indicators is interpreted and synthesized to assess the progress of sustainable development and the report of assessment serves as a means by which to provide policy-makers, the public, and relevant parties of interest with clear information [10]. Indicator-based assessments and sustainable development reports can use a range of different approaches or quantitative methods (such as technique for order preference by similarity to an ideal solution [11], analytic hierarchy process [12], data environment analysis [13]) to assess progress on agreed targets or goals of sustainable development, report development trends, and present and communicate outcomes [10]. The approaches and methods applied depend on many factors, including the size of the used indicator framework, the availability of indicators' datasets, and the assessments' audience and their needs. The use of easy-to-interpret symbols has become a main feature of such reports to improve communication [8]. Therefore, recent indicator-based assessments and reports of sustainable development can provide an SDG assessment analysis report with useful case studies, such as providing ways for selecting the indicators or a range of different approaches or quantitative methods like the study of Zhang [12] and Guo et al. [13]. Based on those prevenient research and assessments of sustainable development, countries and organizations around the world have conducted a series of initial indicator-based assessments of SDGs at different scales, including assessments of baselines, trend analysis, and benchmarking of progress since 2016 [7,14-31], though there were also weaknesses and problems of these SDG assessments [32]. Among those assessments, Kroll [15] completed the world's first inter-country SDG current condition assessment and composite SDG index, which included 34 countries after selecting 34 indicators corresponding to 17 SDGs, made the relative calculation method, and provided following studies with a brand-new starting point. Furthermore, Nejdawi et al. [16] selected 56 indicators corresponding to 17 SDGs from 22 countries within the four divisions of the Arab region and established a corresponding computation method. It was the first study that employed graphic visualization to illustrate current SDG performance and development trends over the past 20 years for each individual indicator in the entire region. They also used an embedded integrated framework to analyze the interconnection and dynamic change of SDGs in the area. Sachs et al. [19] introduced even more indicators, basing their analysis on the study of Kroll [15] and including 77 indicators corresponding to 17 SDGs. The study of Sachs et al. [19] eventually analyzed and assessed the SDGs performance and the ranking of SDGs progress in 149 countries in that year. Based on the study of Sachs et al. [19], Clark et al. [21] selected 35 indicators and a corresponding computation method to specifically assess the SDG performance and ranking of 15 EU countries from 2000 to 2014. Fullman et al. [22], instead of targeting the performance of all SDGs, focused on measuring 37 indicators out of a total of 50 health-related indicators from 1990 to 2019. The study of Fullman et al. [22] included the performance and ranking of health-related SDGs in 188 countries in 2016 and predicted the condition of health-related indicators in those countries by the year 2030. Based on two previous studies, Sachs et al. [19] and Sachs et al. [25], in 2018 Sachs et al. [30] selected 88 indicators corresponding to 17 SDGs to analyze and assess SDG performance and ranking in 156 countries in that year. It was the first study that employed historical trend data and estimated the speed at which a country realizes SDGs and whether or not such speed could help that country accomplish their SDGs by 2030.

Among the 244 indicators included in the SDG framework published by the UN, 9 indicators belong to two or more goals, thus making the total number of indicators actually 23 [33]. Of those, some indicators are an indicator set, which can include many different time-series datasets of different types, e.g., sex, age, or location [34]. In comparison, the selected indicators in the previous research reports are not only limited in number but also lack specific types for each indicator, resulting in failure to completely assess the 17 SDGs. In addition, research rarely concentrates on developing countries 
located in the Central and South Asian regions that are stressed in "the Belt and Road Initiative" (BRI). The BRI aims to promote the orderly and free flow of economic factors, the efficient allocation of resources and the deep integration of markets. Besides, it aims to promote the coordination of economic policies among countries and carries out national cooperation on a larger scale, higher standard, and deeper level to jointly create an open, inclusive and balanced regional economic cooperation framework [35]. The BRI is committed to establishing and strengthening the partnership of countries, building a comprehensive, multi-level and complex interconnection network to achieve diversified, independent, balanced and sustainable development of countries [36]. In terms of the final vision, the BRI is consistent with the SDGs.

In this context, this paper strived to be comprehensive in terms of constructing an indicator framework. It eventually used 209 indicators as well as indicator sets that include 429 specific indicators corresponding to 17 SDGs in three dimensions, i.e., economy, society, and environment. Specifically, economic dimension included 141 specific indicators corresponding to SDG 8 (promote sustained, inclusive and sustainable economic growth, full and productive employment and decent work for all), SDG 9 (build resilient infrastructure, promote inclusive and sustainable industrialization and foster innovation), SDG 10 (reduce inequality within and among countries) and SDG 17 (strengthen the means of implementation and revitalize the global partnership for sustainable development); the social dimension included 220 specific indicators corresponding to SDG 1 (end poverty in all its forms everywhere), SDG 2 (end hunger, achieve food security and improved nutrition and promote sustainable agriculture), SDG 3 (ensure healthy lives and promote well-being for all at all ages), SDG 4 (ensure inclusive and equitable quality education and promote lifelong opportunities for all), SDG 5 (achieve gender equality and empower all women and girls) and SDG 16 (promote peaceful and inclusive societies for sustainable development, provide access to justice for all and build effective, accountable and inclusive institutions at all levels); the environmental dimension included 220 specific indicators corresponding to SDG 6 (ensure availability and sustainable management of water and sanitation for all), SDG 7 (ensure access to affordable, reliable, sustainable and modern energy for all), SDG 11 (make cities and human settlements inclusive, safe, resilient and sustainable), SDG 12 (ensure sustainable consumption and production patterns), SDG 13 (take urgent action to combat climate change and its impacts) and SDG 15 (protract, restore and promote sustainable use of terrestrial ecosystems, sustainably manage forests, combat desertification, and halt and reverse land degradation and halt biodiversity loss). It also proposed a relatively new computation method based on past case studies to not only analyze the annual progress of economic, social, environmental and the overall SDGs from 2000 to 2017 of two typical countries Kazakhstan and Kyrgyzstan in Central Asia, but also conducted a comparative analysis over the important breakpoints of three-dimensional SDG trends in performance over those 18 years and causes of the breakpoints. In particular, this paper is the first to combine the concept of using the Chow test to verify the breakpoint and aid the analysis of the SDG trend in performance over those 18 years. It has the potential to assist the governmental review of the trends and changes in SDG performance as well as indicate possible causes of these changes, cope with future catastrophes that could have an impact on the SDG performance in those countries, and formulate relevant policy for sustainable development. Moreover, the research framework constructed in this paper can be applied for the analysis of SDGs of different nations around the world, further helps scientifically understand the development coupling mechanism and its impact path of the national society, economy and environment systems included within the BRI. This study could thereby lay the groundwork for coordinated planning on the strategic decision-making level to support the construction under the BRI by different countries and realize the win-win cooperation among the nations.

In the following sections, we firstly described an overview of the sample area, and we secondly constructed a detailed methodological framework including five steps. Thirdly, we presented the results of the assessment and the analysis of results and discussed the advantages and challenges of the assessment framework. Finally, we presented the conclusions of the paper. 


\section{Materials and Methods}

Based on the two research areas, Kazakhstan and Kyrgyzstan, we first constructed the methodological and indicators framework of this paper with time-series databases of the SDGs for the two countries. Second, we considered an indicator as a forward indicator if the SDG indicator represents the meaning that the higher the value, the better the sustainable development, and we considered an indicator as an inverse indicator if the SDG indicator represents the meaning that the smaller the value, the better the sustainable development. After differentiating the forward and inverse indicators contained within the indicator framework this paper used, we unified the direction of the indicator data. Third, we normalized all of the indicator data, and fourth, we obtained the score of each goal by calculating the average value. Fifth, we obtained the score for the economic, societal and environmental SDGs, as well as the total score of the SDGs of these two countries. Finally, we conducted a breakpoint test based on the scores of the SDGs for the society, economy, and environment.

\subsection{An Overview of the Sample Area}

Central Asia (Figure 1) covers the area from the western Caspian Sea to eastern China and from northern Russia to southern Afghanistan. This area comprises five main countries: Kazakhstan, Kyrgyzstan, Tajikistan, Turkmenistan, and Uzbekistan, with a total area of 4,003,451 $\mathrm{km}^{2}$ and a population of about 105 million [37]. Table 1 shows the basic characteristics of Kazakhstan and Kyrgyzstan.

With an area of 2,724,900 $\mathrm{km}^{2}$ and a population of around 17.4 million people [38], Kazakhstan is the ninth largest country in the world by area and the largest landlocked country in the world [39]. Kazakhstan is a transcontinental country largely located in Asia, with a small area located in the western Urals. Its terrain includes the Caspian Sea to the west, the Altay Mountains to the east, the plains of Western Siberia to the north, and the oases and deserts of Central Asia to the south, with only $3 \%$ of its territory being a wooded area. Its climate type is continental climate, with warm to hot (mostly humid) summers and cold (sometimes extremely cold) winters. In 1991, the dissolution of the Soviet Union occurred and Kazakhstan became independent. Since then, Kazakhstan has been a unitary republic with Nursultan Nazarbayev as the only President to date. The politic system is composed of the Majilis (the lower house) and the Senate (the upper house). Kazakhstan has the largest and strongest performing economy in Central Asia. In 2018, the GDP of Kazakhstan was \$195 billion and its GDP per capita was $\$ 10,447$ [40]. Its economy has been beneficial from its large amounts of natural resources (such as oil, gas, and uranium), heavy industry (ferrous and non-ferrous metals), and agricultural products. Wedged between the two powerful countries of Russia and China, the geopolitics of Kazakhstan are vital. It is also a potential gateway to the Caspian Sea and on to Europe, which has been the most significant partner country of China's BRI [41].

The Kyrgyzstan Republic is a landlocked country in the southeast corner of Central Asia with $199,900 \mathrm{~km}^{2}$ of land and a population of 5.62 million [37]. It borders north to west and southwest from Kazakhstan to Uzbekistan, and southwest to east from Tajikistan to China. With mountains covering $80 \%$ of the country, Kyrgyzstan has few plains and the altitudes of most areas are between 500 and 1000 meters. Kyrgyzstan has a temperate continental climate with moderate precipitation, but in recent years the amount of precipitation has been decreasing [42]. Kyrgyzstan does not have significant deposits of oil or natural gas; however, it has some mineral resources such as gold, which is essential in this state's development plan [43]. Kyrgyzstan declared its independence in 1991 after the dissolution of the Soviet Union. According to the 1993 constitution, the form of government is a unitary parliamentary republic, however, in practice, the country was more like a presidential republic with a strong president and weak parliament, making it a nominal parliamentary republic. The 2010 constitution allowed Kyrgyzstan to remain a unitary parliamentary republic but with a stronger parliament, rendering it a true parliamentary republic. Kyrgyzstan's economy was heavily influenced by the dissolution of the Soviet Union resulting in a huge loss in its market. It is the second poorest country in Central Asia, with a total GDP of $\$ 24.356$ billion and $\$ 3,812$ per capita [44]. Kyrgyzstan's economy is supported by 
the industries of agriculture and the raising of livestock. Kyrgyzstan is located in the center of Central Asia and serves as a "water tower" and gateway for Central Asia, making its geopolitics both unique and vital.

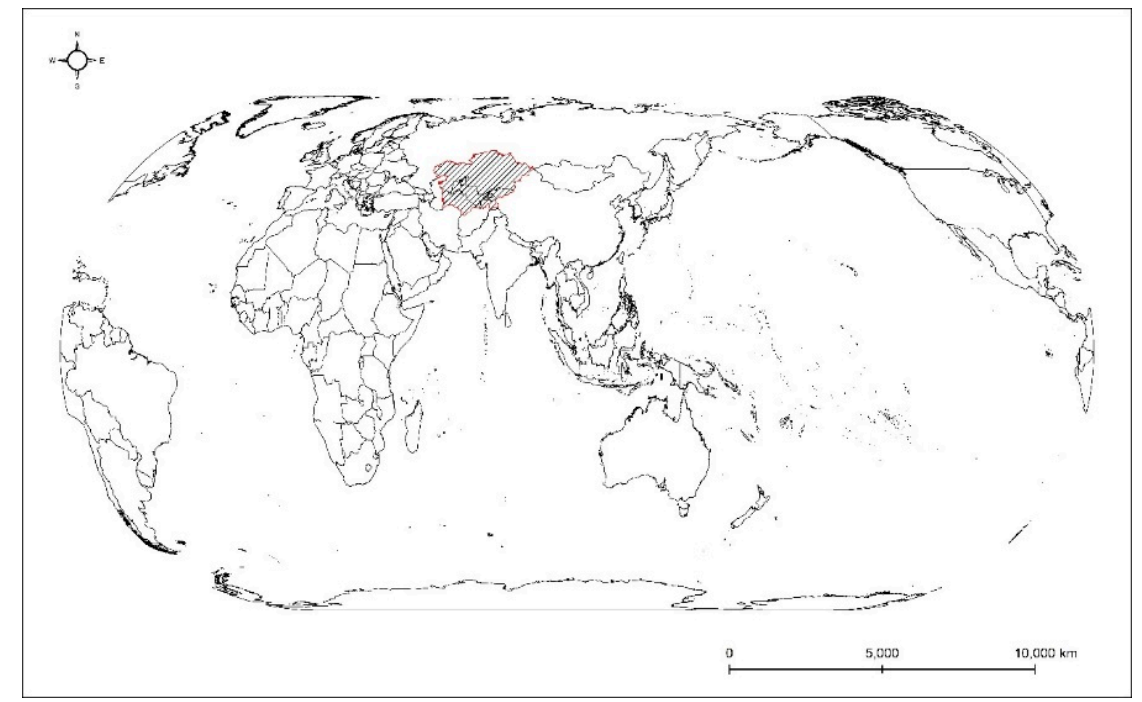

(a)

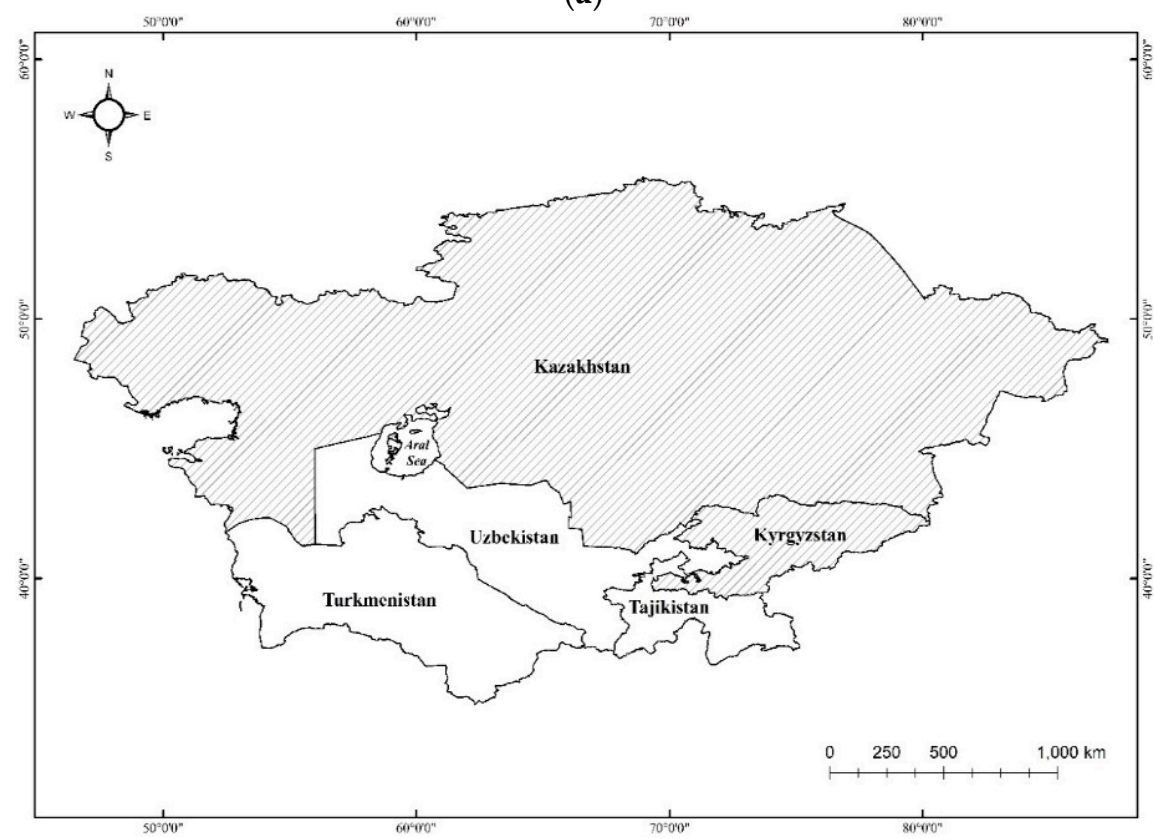

(b)

Figure 1. The location of the sample area of the research. (a) The location of Central Asia on the global map. Note: the shaded area is Central Asia; (b) The map of Central Asia and the sample area of the research, i.e., Kazakhstan and Kyrgyzstan. Note: the shaded area is Kazakhstan and Kyrgyzstan.

Table 1. Basic characteristics of Kazakhstan and Kyrgyzstan.

\begin{tabular}{cccccc}
\hline Country & $\begin{array}{c}\text { Independent } \\
\text { Year }\end{array}$ & $\begin{array}{c}\text { Area } \\
\left.\mathbf{( k m}^{2}\right)\end{array}$ & $\begin{array}{c}\text { Population } \\
\text { (million) }\end{array}$ & Climate Type & $\begin{array}{c}\text { 2018 GDP } \\
\text { (\$ billion) }\end{array}$ \\
\hline Kazakhstan & 1991 & $2,724,900$ & 17.4 & Continental & 195 \\
\hline Kyrgyzstan & 1991 & 199,900 & 5.62 & $\begin{array}{c}\text { Temperate } \\
\text { Continental }\end{array}$ & 24.356 \\
\hline
\end{tabular}




\subsection{Constructing an SDG Database}

The selection of indicators and construction of the database consisted primarily of the following four standards. First, the 2030 Agenda for Sustainable Development [45] and the SDGs are high on the agenda for most countries around the world. In 2015, the Inter-Agency Expert Group on Sustainable Development Goals Indicators (IAEG-SDGs) held the first meeting, and it was tasked with designing indicators and methods corresponding to SDGs at the global level and disseminating them to countries that could be used to collect data describing the global progress towards sustainable development. The IAEG-SDGs initially developed 231 indicators and classified them into 3 tiers (Tier I, Tier II and Tier III) based on statistical methods and the ease of data acquisition [46,47]. However, due to the need for a large amount of data support to establish a complete indicators' framework, this work continued until 2017, including: establishing and improving the indicators' tiers, developing a process for reviewing related methods of indicators, establishing the approval mechanism for necessary amendments of indicators in future, reviewing the situation of data acquisition on the indicators in Tier I and Tier II, planning to expand the coverage of the indicators' data in Tier II, and discussing the use of multi-purpose indicators [47]. In 2017, the United Nations Statistical Commission eventually adopted the global indicators' framework (comprised of 232 indicators) for measuring the UN Agenda 2030 for Sustainable Development [45] and 17 SDGs and their 169 targets, and the UN General Assembly subsequently endorsed the framework [33]. Therefore, it can be seen that this is a global indicator framework that has been jointly researched, established and improved by plenty of global organizations and experts for a long time. This indicator framework can be very instructive for the selection of indicators for assessing SDGs. For example, when researchers want to develop adequate indicators for assessing SDG 16 (promote peaceful and inclusive societies for sustainable development, provide access to justice for all and build effective, accountable and inclusive institutions at all levels), it is a basic requirement to have deep and ample knowledge and understanding of the phenomena or situation of violence, crime, justice, peace and government. Without it, the indicators developed will certainly decrease and reorient the content of the goal [48]. Thus, as few individuals or organizations can master all the challenging content proposed by 17 SDGs, this indicator framework proposed by IAEG-SDGs may be the most appropriate SDG indicator framework for reference and use by researchers. It is authoritative and can be reductionist of the phenomena they measure (some researchers regard it as a minimalist expression of the 2030 Agenda for Sustainable Development $[45,48]$ ), although it may represent a huge statistical challenge and some indicators may not be accurately quantified $[49,50]$. Therefore, to cover all 17 SDGs, based on this authoritative indicator framework and the situation of two countries' data collection in the UN SDGs database, we selected as many indicators as possible with data from 2000 to 2017 [51]. Second, of the 232 indicators proposed by the UN, some indicators such as 8.1.1 (annual growth rate of real GDP per capita (\%)) are independent indicators without any classification (indicator 123 in Table 2), while others are actually a collection of indicators, which contain a large number of time series data of different and specific categories such as gender, age, or location. For example, in the UN SDGs' framework, indicator 4.2.2 (participation rate in organized learning (one year before the official primary entry age), by sex (\%)) can be actually classified as three specific indicators according to male, female, and all gender (both sexes), and these three specific indicators all belong to the set of indicator 4.2.2. Thus, this paper divided the indicator set 87 into 3 specific indicators shown in Table 2. Similarly, for this kind of indicator set, we collected different time series data according to their classification as far as possible and regarded them as different independent specific indicators (Table S1 and S2). Third, the SDG framework proposed by the UN is from a global perspective; however, due to differences in terms of the sustainable development issues faced by different countries, each country has its own priorities in the acquisition of data in terms of its type and quality. For example, Kazakhstan is located next to the Aral Sea (Figure 1b), which is vital for Kazakhstan's economic, social, and environmental sustainable development. Thus, Kazakhstan has been paying attention to SDG 14 (conserve and sustainably use the oceans, seas and marine resources for sustainable development) and collecting the related data. As for Kyrgyzstan, 
although it has some important lakes and rivers such as Issyk lake, it did not have full priorities in the collection of SDG 14-related data. Thus, indicators with very limited data available in the UN SDG database were excluded from the indicator framework in this paper. After comparing the databases for the two countries (Table S1 and S2), only identical indicators in both databases were retained. Indicators (or indicator sets) for which only one country's database had data while the other country's database did not, were deleted. For example, for SDG 14, there were only time series data collected for target 14.5 (by 2020, conserve at least $10 \%$ of coastal and marine areas, consistent with national and international law and based on the best available scientific information) in the Kazakhstan database (Table S2), while in the Kyrgyzstan database (Table S1), there were no time series data for indicators of goal 14 at all. Thus, this paper did not carry out statistical analysis on the performance of SDG 14 (conserve and sustainably use the oceans, seas and marine resources for sustainable development) in two countries, and we removed 147 specific indicators from 729 specific indicators of the Kyrgyzstan indicator framework (Table S1), and 214 specific indicators from 795 specific indicators of the Kazakhstan indicator framework (Table S2). Both countries' indicator frameworks eventually had the same 581 specific indicators (Table S3). However, since five indicators or indicator sets repeat under two or three different targets (listed in Table S3), the actual total number of indicators and indicator sets in the list is 209 , including 429 specific indicators. Fourth, due to the different frequencies of measurement for each of the indicators among the countries, there were obvious gaps and deficiencies in data collection, and different methods of interpolating missing data will result in different emphasis and errors, which can easily result in very different outcomes. Therefore, this paper did not interpolate missing data, and only focused on available data. Finally, 209 indicators and indicator sets were used in the indicator framework, including 429 specific indicators, corresponding to 16 SDGs, except goal 14 from 17 SDGs (Table S3). 
Table 2. The part of the complete indicators framework used in this paper.

\begin{tabular}{|c|c|c|c|c|c|c|}
\hline SDG & $\begin{array}{c}\text { Dimension of the } \\
\text { SDG }\end{array}$ & SDG Target & $\begin{array}{l}\text { Indicator or } \\
\text { Indicator Set }\end{array}$ & Tier Classification & Specific Indicator & Indicator's Direction \\
\hline $\begin{array}{l}\text { 1: End poverty in all } \\
\text { its forms everywhere }\end{array}$ & Society & $\begin{array}{l}\text { 1.a: Ensure significant mobilization } \\
\text { of resources from a variety of } \\
\text { sources, including through enhanced } \\
\text { development cooperation, in order } \\
\text { to provide adequate and predictable } \\
\text { means for developing countries, to } \\
\text { implement programmes and policies } \\
\text { to end poverty in all its dimensions }\end{array}$ & 37 & II & $\begin{array}{l}\text { Proportion of total government } \\
\text { spending on essential services, } \\
\text { education (\%) }\end{array}$ & Forward \\
\hline \multirow{3}{*}{$\begin{array}{l}\text { 4: Ensure inclusive } \\
\text { and equitable quality } \\
\text { education and } \\
\text { promote lifelong } \\
\text { opportunities for all }\end{array}$} & \multirow[t]{3}{*}{ Society } & \multirow{3}{*}{$\begin{array}{l}\text { 4.2: By } 2030 \text {, ensure that all girls and } \\
\text { boys have access to quality early } \\
\text { childhood development, care and } \\
\text { pre-primary education so that they } \\
\text { are ready for primary education }\end{array}$} & \multirow[t]{3}{*}{87} & \multirow[t]{3}{*}{ I } & $\begin{array}{l}\text { Participation rate in organized } \\
\text { learning (one year before the official } \\
\text { primary entry age), both sex (\%) }\end{array}$ & \multirow[t]{3}{*}{ Forward } \\
\hline & & & & & $\begin{array}{l}\text { Participation rate in organized } \\
\text { learning (one year before the official } \\
\text { primary entry age), female (\%) }\end{array}$ & \\
\hline & & & & & $\begin{array}{l}\text { Participation rate in organized } \\
\text { learning (one year before the official } \\
\text { primary entry age), male (\%) }\end{array}$ & \\
\hline $\begin{array}{l}\text { 8: Promote sustained, } \\
\text { inclusive and } \\
\text { sustainable economic } \\
\text { growth, full and } \\
\text { productive } \\
\text { employment and } \\
\text { decent work for all }\end{array}$ & Economy & $\begin{array}{l}\text { 8.1: Sustain per capita economic } \\
\text { growth in accordance with national } \\
\text { circumstances and, in particular, at } \\
\text { least } 7 \text { per cent gross domestic } \\
\text { product growth per annum in the } \\
\text { least developed countries }\end{array}$ & 123 & I & $\begin{array}{l}\text { Annual growth rate of real GDP per } \\
\text { capita (\%) }\end{array}$ & Forward \\
\hline \multirow{2}{*}{$\begin{array}{l}\text { 11: Make cities and } \\
\text { human settlements } \\
\text { inclusive, safe, } \\
\text { resilient and } \\
\text { sustainable }\end{array}$} & \multirow[t]{2}{*}{ Environment } & \multirow{2}{*}{$\begin{array}{l}\text { 11.6: By } 2030 \text {, reduce the adverse per } \\
\text { capita environmental impact of cities, } \\
\text { including by paying special attention } \\
\text { to air quality and municipal and } \\
\text { other waste management }\end{array}$} & \multirow[t]{2}{*}{189} & \multirow[t]{2}{*}{ I } & $\begin{array}{l}\text { Annual mean levels of fine particulate } \\
\text { matter in cities, all area's population } \\
\text { (micrograms per cubic metre) }\end{array}$ & \multirow[t]{2}{*}{ Inverse } \\
\hline & & & & & $\begin{array}{l}\text { Annual mean levels of fine particulate } \\
\text { matter in cities, urban population } \\
\text { (micrograms per cubic metre }\end{array}$ & \\
\hline
\end{tabular}




\subsection{The Differentiation of Forward and Inverse Indicators}

Sustainability indicators can use greater or smaller values to correspondingly explain the situation where the indicator reaches or nears the ideal condition [53]. This paper used an indicator's direction to describe such an attribute of an indicator, which has been described by different terms in existing literature, such as "direct correlation with utility" or "inverse correlation with utility" [54], "positive impact" or "negative impact" [55], and "criteria is to maximize" or "criteria is to minimize" [56]. In this paper, an indicator was considered as a forward indicator if the SDG indicator represented the meaning that the higher the value, the better the sustainable development, e.g., indicator 37: proportion of total government spending on essential educational services (\%) shown in Table 2. The higher the government's spending on essential educational services, the greater the value of the indicator 37 data, the better the sustainable development of the country. An indicator would be considered as an inverse indicator if the SDG indicator represented the meaning that the smaller the value, the better the sustainable development, e.g., indicator set 189, including two specific indicators (annual mean levels of fine particulate matter in cities, all area's population (micrograms per cubic meter); annual mean levels of fine particulate matter in cities, urban population (micrograms per cubic meter)) shown in Table 2. The lower the content of fine particulate matter, the smaller the value of the indicator set 189 data, the better the sustainable development of the country.

Based on the type of data value, the specific methods for turning an inverse indicator into a forward indicator in this paper can be categorized into the following:

1. If there is a forward indicator set $\mathrm{A}=\left\{\mathrm{d}_{1}, \mathrm{~d}_{2}, \cdots, \mathrm{d}_{n}\right\}, i=1 \sim n, \mathrm{~d}_{i}$ is a real number, and all $\mathrm{d}_{i}>=0$ or all $\mathrm{d}_{i}<0$, then the processed element $\mathrm{e}_{i}=\mathrm{d}_{i}$, the set $\mathrm{E}=\left\{\mathrm{e}_{1}, \mathrm{e}_{2}, \cdots, \mathrm{e}_{n}\right\}, \mathrm{e}_{i}$ is a real number, where $A$ and $E$ are mapped to each other;

2. If there is a forward indicator set $\mathrm{A}=\left\{\mathrm{d}_{1}, \mathrm{~d}_{2}, \cdots, \mathrm{d}_{n}\right\}, i=1 \sim n, \mathrm{~d}_{i}$ is a real number, and the number of $i$ elements with $\mathrm{d}_{i}>=0$ and $\mathrm{d}_{i}<0$ is not less than 1 , take $\mathrm{d}_{\min }=\min \{\mathrm{A}\}$, the processed element $\mathrm{e}_{i}=\mathrm{d}_{i}-\mathrm{d}_{\min }$, its set $\mathrm{E}=\left\{\mathrm{e}_{1}, \mathrm{e}_{2}, \cdots, \mathrm{e}_{n}\right\}, \mathrm{e}_{i}$ is a real number, where $\mathrm{A}$ and $\mathrm{E}$ are mapped to each other;

3. If there is an inverse indicator set $\mathrm{B}=\left\{\mathrm{d}_{1}, \mathrm{~d}_{2}, \cdots, \mathrm{d}_{n}\right\}, i=1 \sim n, \mathrm{~d}_{i}$ is a real number, and all $\mathrm{d}_{i}>=0$, take $\mathrm{d}_{\max }=\max \{\mathrm{B}\}$, and the processed element $\mathrm{e}_{i}=\left|\mathrm{d}_{i}-\mathrm{d}_{\max }\right|$, its set $\mathrm{E}=\left\{\mathrm{e}_{1}, \mathrm{e}_{2}, \cdots, \mathrm{e}_{n}\right\}, \mathrm{e}_{i}$ is a real number, where $\mathrm{B}, \mathrm{E}$ are mapped to each other;

4. If there is an inverse indicator set $\mathrm{B}=\left\{\mathrm{d}_{1}, \mathrm{~d}_{2}, \cdots, \mathrm{d}_{n}\right\}, i=1 \sim n, \mathrm{~d}_{i}$ is a real number, and all $\mathrm{d}_{i}<=0$, the processed element $\mathrm{e}_{i}=\left|\mathrm{d}_{i}\right|$, its set $\mathrm{E}=\left\{\mathrm{e}_{1}, \mathrm{e}_{2}, \cdots, \mathrm{e}_{n}\right\}, \mathrm{e}_{i}$ is a real number, where $\mathrm{B}$ and $\mathrm{E}$ are mapped to each other;

5. If there is an inverse indicator set $\mathrm{B}=\left\{\mathrm{d}_{1}, \mathrm{~d}_{2}, \cdots, \mathrm{d}_{n}\right\}, i=1 \sim n, \mathrm{~d}_{i}$ is a real number, and the number of $i$ elements with $\mathrm{d}_{i}>=0$ and $\mathrm{d}_{i}<0$ is not less than 1 , take $\mathrm{d}_{\max }=\operatorname{Max}\{\mathrm{B}\}$, the processed element $\mathrm{e}_{i}=\left|\mathrm{d}_{i}-\mathrm{d}_{\text {max }}\right|$, its set $\mathrm{E}=\left\{\mathrm{e}_{1}, \mathrm{e}_{2}, \cdots, \mathrm{e}_{n}\right\}, \mathrm{e}_{i}$ is a real number, where $\mathrm{B}, \mathrm{E}$ are mapped to each other.

\subsection{The Normalization of Indicator Data}

In sustainability assessment, normalization is the conversion of the original unit of measure to the common unit of measure to conduct a comparison or include it in the calculation of the sustainability score. This process is also referred to as unit scaling or standardization, in which the term name can vary depending on the subject and the function usage [53]. When indicator units are different, normalization is considered an important step before aggregation. The use of different methods for normalization and aggregation can yield extremely different composite sustainability scores $[3,5]$. The normalization method adopted in this paper is as follows:

Suppose there are two countries' original databases, i.e., $A=\left\{a_{1}, a_{2}, \ldots, a_{n}\right\}, B=\left\{b_{1}, b_{2}, \ldots, b_{n}\right\}$, $i=1 \sim n$, where $\mathrm{a}_{i}=$ (a_caption, $\mathrm{a} \_$value), $\mathrm{b}_{i}=$ (b_caption, $\mathrm{b} \_$value), $\mathrm{a} \_$caption and $\mathrm{b} \_$caption are the ordered identification groups of elements $a_{i}$ and $b_{i}, a_{-}$value and $b_{-}$value are the value vector groups of the elements $\mathrm{a}_{i}$ and $\mathrm{b}_{i}$, respectively; if there are $k$ values, $j$ satisfyies: $\mathrm{a}_{k}$ : $\mathrm{a}_{-}$caption $=\mathrm{b}_{j}$ : $\mathrm{b}_{-}$caption, then take $P_{M a x}=\max \left\{a_{k}: a_{-}\right.$value, $b_{j}: b_{-}$value $\}$, let the element $a p=\left(a \_c a p t i o n, a p \_v a l u e\right), b p=\left(b \_c a p t i o n\right.$, 
bp_value), then ap_value $=\mathrm{a} \_$value $/ \mathrm{P}_{\mathrm{Max}}, \mathrm{bp} \_$value $=\mathrm{b} \_$value $/ \mathrm{P}_{\mathrm{Max}}$, finally, after normalizing the two countries' databases, we obtain the data set $\mathrm{AP}=\left\{\mathrm{ap}_{1}, \mathrm{ap}_{2}, \ldots, \mathrm{ap}_{n}\right\}, \mathrm{BP}=\left\{\mathrm{bp}_{1}, \mathrm{bp}_{2}, \ldots, \mathrm{bp}_{n}\right\}$.

\subsection{Aggregation}

After normalization, the performance of each SDG in the two countries Kazakhstan and Kyrgyzstan (named country A and B in this section) can be reflected through calculating the arithmetic mean of each SDG and regarding the mean value as the score of each goal. The method is as follows:

For the first country A, suppose there is a Goal $i(1 \leq i \leq 17)$, Goal $i$ has $j(j \geq 1)$ indicators, and make $\mathrm{A}_{\text {Goal } i}^{k}(p)$ represent the normalized data of indicator $p(1 \leq p \leq j)$ of Goal $i$ in year $k(k=2000$, $2001, \ldots, 2017)$, then the score of Goal $i$ in year $k$ is $\mathrm{A}_{\text {Goal } i^{\prime}}^{k}$

$$
\mathrm{A}_{\mathrm{Goal} i}^{k}=\frac{\mathrm{A}_{\mathrm{Goal} i}^{k}(1)+\mathrm{A}_{\mathrm{Goal} i}^{k}(2)+\cdots+\mathrm{A}_{\mathrm{Goal} i}^{k}(j)}{j}, \mathrm{i}=1,2, \cdots, 17 ; \mathrm{k}=2000,2001, \cdots, 2017
$$

After calculating the scores of Goal $\mathrm{i}$ from 2000 to 2017 in turn, we get $\mathrm{A}_{\text {Goal } i}^{2000}$ $\mathrm{A}_{\text {Goal } i}^{2001} \cdots, \mathrm{A}_{\text {Goal } i}^{2017}(i=1,2, \ldots, 17)$.

For the other country B, after using the same steps, we get the scores of Goal $i$ from 2000-2017 as $\mathrm{B}_{\mathrm{Goal} i}^{2000}, \mathrm{~B}_{\mathrm{Goal} i}^{2001} \cdots, \mathrm{B}_{\mathrm{Goal} i}^{2017}(i=1,2, \ldots, 17)$.

After calculating the score of each goal, the constructed 17 SDGs need to be weighted and aggregated to obtain the annual total score of SDGs to measure the overall SDG performance of the two countries in different years. In the SDG assessment, different weights for each goal could generate a major impact on the SDG performance results for the countries. Just like other composite indices do not have a consensual answer on the weighting problem, different research groups also failed to reach any agreement over the weighting distribution in terms of SDGs $[25,57]$. As few individuals or organizations can master all the challenging content proposed by SDG, flexible weighting might encourage countries to perform easy goals and overlook goals that are equally important and demand further in-depth transformation. Aggregation for SDGs proceeds in two steps in this paper. First, based on the UN's interpretation of SDGs and other relevant studies referred to SDGs classification [21,27-29,58-60], the 17 SDGs were aggregated into three general dimensions, i.e., economy, including SDG 8 (promote sustained, inclusive and sustainable economic growth, full and productive employment and decent work for all), SDG 9 (build resilient infrastructure, promote inclusive and sustainable industrialization and foster innovation), SDG 10 (reduce inequality within and among countries) and SDG 17 (strengthen the means of implementation and revitalize the global partnership for sustainable development); society, including SDG 1 (end poverty in all its forms everywhere), SDG 2 (end hunger, achieve food security and improved nutrition and promote sustainable agriculture), SDG 3 (ensure healthy lives and promote well-being for all at all ages), SDG 4 (ensure inclusive and equitable quality education and promote lifelong opportunities for all), SDG 5 (achieve gender equality and empower all women and girls) and SDG 16 (promote peaceful and inclusive societies for sustainable development, provide access to justice for all and build effective, accountable and inclusive institutions at all levels); and environment, including SDG 6 (ensure availability and sustainable management of water and sanitation for all), SDG 7 (ensure access to affordable, reliable, sustainable and modern energy for all), SDG 11 (make cities and human settlements inclusive, safe, resilient and sustainable), SDG 12 (ensure sustainable consumption and production patterns), SDG 13 (take urgent action to combat climate change and its impacts), SDG 14 (conserve and sustainably use the oceans, seas and marine resources for sustainable development) and SDG 15 (protract, restore and promote sustainable use of terrestrial ecosystems, sustainably manage forests, combat desertification, and halt and reverse land degradation and halt biodiversity loss). Because the three dimensions are clearly interdependent and interconnected, it could therefore be argued that some social SDGs should be categorized into the dimensions of economy and environment, and vice versa.

To reflect the economic, social, and environmental sustainable development of the two countries we first summed up the scores of all the different annual goals in all three dimensions for each country 
in every year and obtained the SDG scores in terms of the three dimensions of the two countries in different years. Specific methods are as follows:

For country A, we let $A_{\text {social SDGs }}^{k}$ represent the score of the social SDGs in year $k(k=2000$, $2001, \cdots, 2017), A_{\text {economic SDGs }}^{k}$ represents the score of the social SDGs in year $k(k=2000,2001$, $\ldots, 2017)$, and $A_{\text {environmental SDGs }}^{k}$ represents the score of the social SDGs in year $k(k=2000,2001$, $\cdots$, 2017), then we obtain $A_{\text {social SDGs }}^{k}=A_{\text {Goal 1 }}^{k}+A_{\text {Goal 2 }}^{k}+A_{\text {Goal 3 }}^{k}+A_{\text {Goal } 4}^{k}+A_{\text {Goal } 5}^{k}+A_{\text {Goal 16 }}^{k}$ $(\mathrm{k}=2000,2001, \cdots, 2017), \mathrm{A}_{\text {economic SDGs }}^{k}=\mathrm{A}_{\text {Goal } 8}^{k}+\mathrm{A}_{\text {Goal } 9}^{k}+\mathrm{A}_{\text {Goal 10 }}^{k}+\mathrm{A}_{\text {Goal 17 }}^{k}(\mathrm{k}=2000,2001, \cdots$, 2017), and $\mathrm{A}_{\text {environmental SDGs }}^{k}=\mathrm{A}_{\text {Goal } 6}^{k}+\mathrm{A}_{\text {Goal } 7}^{k}+\mathrm{A}_{\text {Goal 11 }}^{k}+\mathrm{A}_{\text {Goal 12 }}^{k}+\mathrm{A}_{\text {Goal 13 }}^{k}+\mathrm{A}_{\text {Goal 14 }}^{k}+\mathrm{A}_{\text {Goal 15 }}^{k}$ $(k=2000,2001, \cdots, 2017)$. For the other country, $B$, after using the same steps, we obtain the scores of three-dimensional SDGs from 2000 to 2017 as $\mathrm{B}_{\text {social SDGs }}^{k} \mathrm{~B}_{\text {economic SDGs' }}^{k}$ and $\mathrm{B}_{\text {environmental SDGs' }}^{k}$ $(\mathrm{k}=2000,2001, \cdots, 2017)$.

Second, we summed up the scores for the two countries' different annual goals and obtained the total SDGs score of the two countries in different years. From the lowest score (0 points) to the highest score (17 points), the higher the score, the better the performance or achievement of the SDGs, and the better the sustainable development level of the country. Specific methods are as follows:

For country A, we still use $A_{\text {Goal } i}^{k}$ to represent the score of Goal $\mathrm{i}$ in the year $\mathrm{k}(\mathrm{k}=2000,2001, \cdots$, 2017), and $A_{\text {total }}^{k}$ means the score of the total SDGs in the year $k(k=2000,2001, \cdots, 2017)$, then we obtain $\mathrm{A}_{\text {total }}^{k}=\sum_{i=1}^{17} \mathrm{~A}_{\text {Goal } i^{\prime}}^{k} \mathrm{k}=2000,2001, \cdots, 2017$. For the other country, B, after using the same steps, we obtain the scores of total SDGs from 2000 to 2017 as $A_{\text {total }}^{k}(k=2000,2001, \cdots, 2017)$.

\subsection{Chow Breakpoint Test}

In order to test the turning points in the time-series data for SDG performance in the three dimensions for those 18 years in the two countries, we performed the Chow breakpoint test for the years between 2000 and 2017 (i.e., 2003-2015). If any dimension in the SDG performance trends had breakpoints, then it could indicate that the performance could generally be divided into two parts, i.e., two development trends, by the breakpoint for those 18 years. Determination of the causes and consequences of the breakpoints requires further analysis based on the nation's actual societal, economic, and environmental conditions. This method of breakpoint analysis, employing the breakpoint test while closely integrating it into the actual conditions in the area, is conducive to the scenario analysis, highlighting of specific issues, policy assessment, and development of model direction selection among and within countries, which tests and supports the performance of SDGs.

The Chow breakpoint test was proposed by Chinese-American Gregory Chi-Chong Chow in 1960 [61], and its principles are: (1) dividing the sample observation into two or more subsets, but in order for the equation to be estimated, it is necessary to require that the number of observations included in each subset is greater than the number of parameters to be estimated by the equation; (2) estimating the equation separately by using each subset and full sample observation values; (3) constructing the F statistic to determine whether the structure of the model has changed significantly by using the residual squared sum estimated through each subset sample (also known as the unrestricted residual squared sum) and residual squared sum estimated through a full-sample observation value (also known as the restricted residual squared sum) [62].

The null hypothesis of the Chow breakpoint test, $\mathrm{H}_{0}$, is that there is no breakpoint. The concrete steps are as follows:

1. Use the full-sample $t=\left(1,2, \cdots, n_{1}, n_{1}+1, n_{2}+2, \cdots, n_{1}+n_{2}\right)$ to perform linear regression of the least squares estimation (OLS) using the model

$$
Y_{t}=\lambda_{1}+\lambda_{2} x_{t}+u_{t}
$$

and obtain RSS; its degree of freedom is $n_{1}+n_{2}-k$ and is marked as $\mathrm{RSS}_{\mathrm{R}}$, and the subscript R represents equal regression parameter constraints for the two subsets; 
2. Use the two subsets $t=\left(1,2, \cdots, n_{1}\right)$ and $t=\left(n_{1}+1, n_{2}+2, \cdots, n_{1}+n_{2}\right)$ to estimate Equation (1) separately and mark RSS as RSS 1 and $\mathrm{RSS}_{2}$, respectively;

3. Construct the F statistic of the Chow test

$$
\mathrm{F}=\frac{\left(\mathrm{RSS}_{\mathrm{R}}-\mathrm{RSS}_{1}-\mathrm{RSS}_{2}\right) /(k+1)}{\left(\mathrm{RSS}_{1}+\mathrm{RSS}_{2}\right) /\left(n_{1}+n_{2}-2(k+1)\right)} \sim \mathrm{F}\left(k+1, n_{1}+n_{2}-2(k+1)\right)
$$

where $k$ represents the number of explanatory variables, and the hypothesis test is performed at a given $1 \%$ significance level by the $\mathrm{F}$ statistic. If $\mathrm{F}$ is greater than the given critical value, the null hypothesis is rejected, indicating that a structural change has occurred and there is a breakpoint; or a Prob. value $<1 \%$ is also indicative that there is a breakpoint. After the Chow test, when there are multiple $\mathrm{F}$ statistic values greater than the critical value, the year with the largest F statistic value is selected as the breakpoint of the SDG performance trend.

\section{Results and Discussion}

\subsection{Quantitative Assessment of Sample Region's SDG Performance}

This section includes four parts. First, we conducted a comparative analysis of the two countries' SDG performance from economic, social, and environmental perspectives. Next, we conducted comparative analysis over the performances of three types of SDGs and then SDGs as a whole from a national perspective. Figure 2 shows the performance of the annual SDGs in all three dimensions for Kyrgyzstan and Kazakhstan from 2000 to 2017. Figure 3 shows the annual total scores of SDGs, i.e., SDG performance in general, in Kyrgyzstan and Kazakhstan from 2000 to 2017.

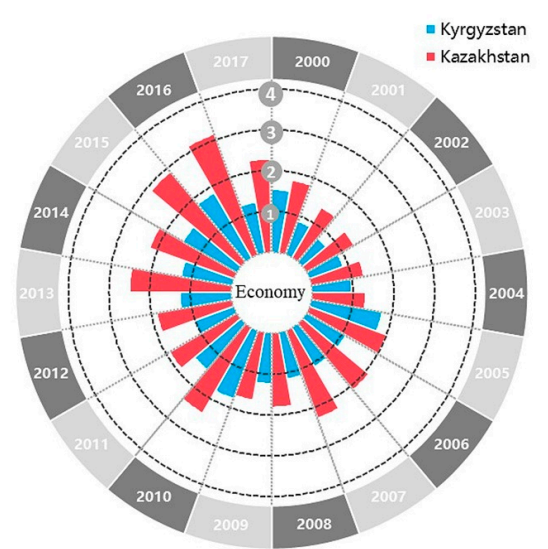

(a)

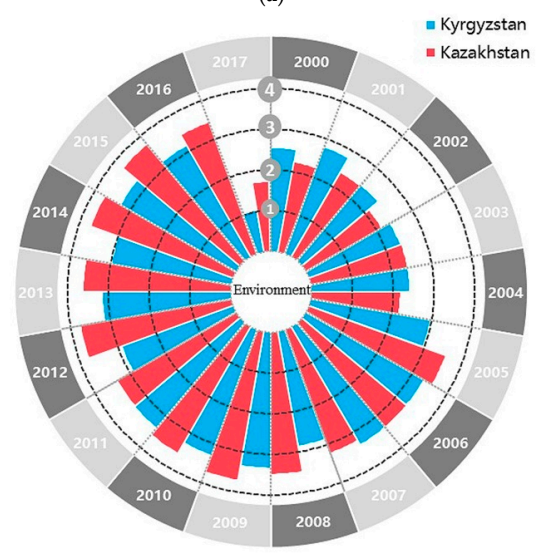

(c)

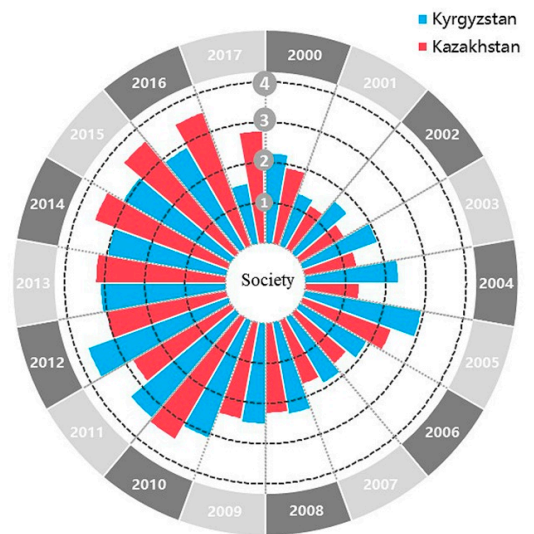

(b)

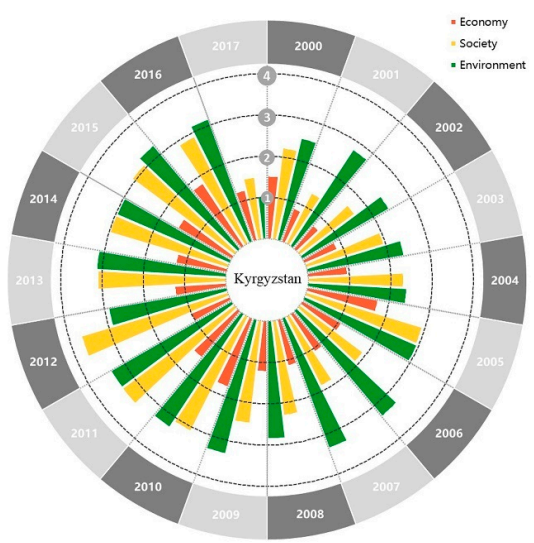

(d)

Figure 2. Cont. 


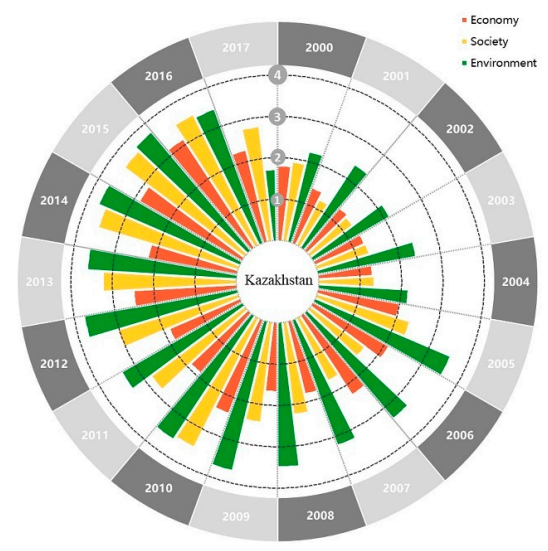

(e)

Figure 2. SDG performance of Kyrgyzstan and Kazakhstan in three dimensions from 2000 to 2017. (a) Economic SDG performance of Kyrgyzstan and Kazakhstan from 2000 to 2017; (b) Social SDG performance of Kyrgyzstan and Kazakhstan from 2000 to 2017; (c) Environmental SDG performance of Kyrgyzstan and Kazakhstan from 2000 to 2017; (d) Three dimensional SDG performance of Kyrgyzstan from 2000 to 2017; (e) Three dimensional SDG performance of Kazakhstan from 2000 to 2017. Note: for Figure $2 \mathrm{a}-\mathrm{c}$, each sector area distinguished by different years has two colored-pillars (red for Kazakhstan and blue for Kyrgyzstan) for representing one-dimensional SDG performance of two countries in one year. The location of four circles consisting of dotted lines represents the score of total SDG performance, and four circles from small to large represent increased scores of 1, 2, 3 and 4 (marked in grey circles), respectively. In each figure, locations of colored-pillars' tops represent the scores of one-dimensional SDG performance of two countries, thus, the longer the colored-pillar, the higher the score of one-dimensional SDG performance, and the better the performance of that dimensional SDGs. For Figure $2 \mathrm{~d}$,e, each sector area distinguished by a different year has three colored-pillars (orange for economy, yellow for society, and green for environment) for representing three different dimensional SDG performances of Kyrgyzstan (Figure 2d) or Kazakhstan (Figure 2e) in one year. The location of four circles consisting of dotted lines in each figure represents the score of three-dimensional SDG performance, and four circles from small to large represent increasing scores of 1, 2, 3 and 4 (marked in grey circles), respectively. Locations of colored-pillars' tops separately represent the scores of dimensional SDG performance of Kyrgyzstan (Figure 2d) or Kazakhstan (Figure 2e); thus, the longer the colored-pillars, the higher the score of dimensional SDG performance, and the better the performance of that dimensional SDG. 


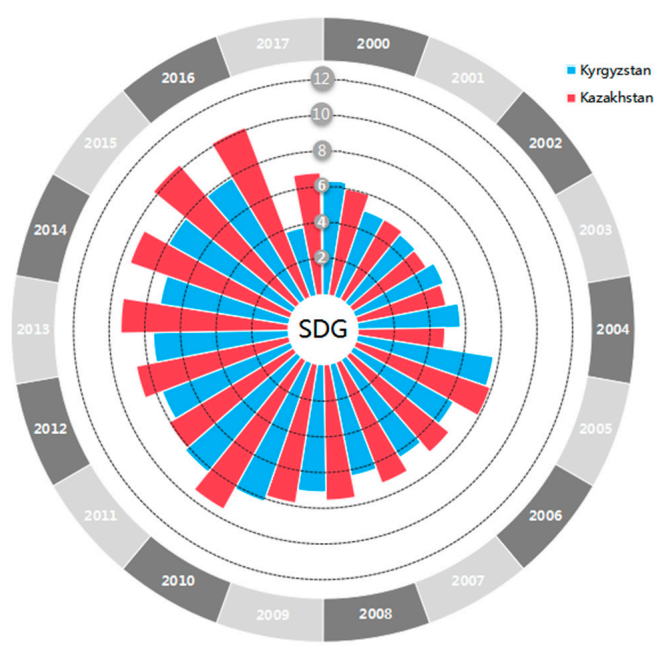

Figure 3. The total SDG performance of Kyrgyzstan and Kazakhstan from 2000 to 2017. Note: each sector area distinguished by different years has two colored-pillars (red for Kazakhstan and blue for Kyrgyzstan) for representing the total SDG performance (except SDG 14 from 17 SDGs) of two countries in one year. The location of six circles consisting of dotted lines represents the score of total SDG performance, and six circles from small to large represent increased scores of 2, 4, 6, 8, 10 and 12 (marked in grey circles), respectively. Locations of colored-pillars' tops represent the scores of the total SDG performance of two countries, thus, the longer the colored-pillar, the higher the score of total SDG performance, and the better the performance of total SDGs.

\subsubsection{Economic SDG Performance}

After we aggregated 16 of 17 SDGs (SDG 14 was excluded) into three dimensions (economy, society, and environment), the economic SDGs contained SDG 8 (promote sustained, inclusive and sustainable economic growth, full and productive employment and decent work for all), SDG 9 (build resilient infrastructure, promote inclusive and sustainable industrialization and foster innovation), SDG 10 (reduce inequality within and among countries) and SDG 17 (strengthen the means of implementation and revitalize the global partnership for sustainable development).

In regard to economic SDG performance (Figure 2a), i.e., total score for goals within this dimension, the score for Kazakhstan displayed a downward trend from 2000 to 2004 (decreasing from 1.81242 to 1.31109), due mainly to its poor performance in representativeness in the policy-making of international economic and financial institutions, speaking rights, foreign investment, and remittance fee, as well as the missing in terms of data regarding the incoming growth rate of the bottom population. However, after steady reinforcing of implementation measures and global cooperation ties, boosting of productive employment, as well as improving financial capability (corresponding to SDG 8: promote sustained, inclusive and sustainable economic growth, full and productive employment and decent work for all, and SDG 17: strengthen the means of implementation and revitalize the global partnership for sustainable development), its score showed an upward trend from 2004 to 2017, increasing to 2.28535. Nevertheless, due to the substantial missing data in terms of the indicator data regarding reducing inequality (corresponding to SDG 10: reduce inequality within and among countries), its score did fluctuate significantly. On the other hand, the score of Kyrgyzstan showed an intense and constant fluctuation for the years between 2000 and 2017, during which, 2000, 2005, 2010, and 2016 witnessed different zeniths (between 1.5 and 1.8) in terms of score, while 2001-2004, 2006-2007, and 2012 witnessed different nadirs (between 0.75 and 1.09). The intensity of this fluctuation was caused by the substantial missing indicator data regarding reducing inequality (corresponding to SDG 10: reduce inequality within and among countries) during the years 2001-2004, 2006-2009, and 2011-2014. In addition, the highest score for the economic SDGs should be 4 points; however, Kyrgyzstan never scored more than 2 points and had long been performing poorly in terms of economic sustainable development due to the dire need for improvement in per capita economic and employment conditions, failure to 
decouple economic growth from environmental degradation, lack of safe working environments, lack of upgrades for disaster-resistant infrastructure, inefficient use of resources, lack of diversified industrial use of technology, weakness in national capacity construction like multi-sectoral finance and technology cooperation, and insufficient resources to strengthen statistical capacity (corresponding to SDG 8: promote sustained, inclusive and sustainable economic growth, full and productive employment and decent work for all, SDG 9: build resilient infrastructure, promote inclusive and sustainable industrialization and foster innovation, and SDG 17: strengthen the means of implementation and revitalize the global partnership for sustainable development).

The best year in terms of economic SDG performance for both Kazakhstan and Kyrgyzstan was 2016, scoring 3.15229 and 1.82786, respectively; the worst year was 2003 for Kazakhstan and 2002 for Kyrgyzstan, scoring 1.30027 and 0.74560 , respectively. In general, Kazakhstan performed better than Kyrgyzstan in terms of economic SDGs.

\subsubsection{Social SDG Performance}

After we aggregated 16 of 17 SDGs (SDG 14 was excluded) into three dimensions (economy, society, and environment), the social SDGs contained SDG 1 (end poverty in all its forms everywhere), SDG 2 (end hunger, achieve food security and improved nutrition and promote sustainable agriculture), SDG 3 (ensure healthy lives and promote well-being for all at all ages), SDG 4 (ensure inclusive and equitable quality education and promote lifelong opportunities for all),SDG 5 (achieve gender equality and empower all women and girls), SDG 16 (promote peaceful and inclusive societies for sustainable development, provide access to justice for all and build effective, accountable and inclusive institutions at all levels).

In social SDG performance (Figure 2b), i.e., the total score of goals within this dimension, the score of Kazakhstan presented three volatile upward trends during the years 2000-2015. The score during 2000 (1.92637)-2001 (1.23912), 2005 (2.35291)-2006 (1.64805), and 2010 (3.50212)-2011 (2.83024) evidently decreased due to its poor performance in capacity to resist social disaster, social welfare policies and measures, building investment for agricultural production capacity (corresponding to SDG 1: end poverty in all its forms everywhere, and SDG 2: end hunger, achieve food security and improved nutrition and promote sustainable agriculture) as well as the substantial missing indicator data regarding promoting peaceful societies and access to justice for all (corresponding to SDG 16: promote peaceful and inclusive societies for sustainable development, provide access to justice for all and build effective, accountable and inclusive institutions at all levels). Additionally, the score during the years 2015-2017 decreased constantly (from 3.63339 to 2.79169) due to the constantly weak performance in capacity to resist social disaster as well as the substantial missing of 2017 indicator data regarding ending poverty (corresponding to SDG 1: end poverty in all its forms everywhere), improving nutrition and promoting sustainable agriculture (corresponding to SDG 2), ensuring healthy lives (corresponding to SDG 3: ensure healthy lives and promote well-being for all at all ages). For Kyrgyzstan, the social SDG performance score showed two upward trends during the years 2000-2012 (from 2.23692 to 3.71334) but then fell consistently during 2012-2017, landing at 1.52113. The scores during the years 2000-2001 and 2005-2007 showed an evident decrease due to the substantial missing of indicator data regarding insufficient investment in agricultural production capacity, time spent on unpaid domestic and care work (corresponding to SDG 5: achieve gender equality and empower all women and girls), and promotion of peaceful societies and access to justice for all (corresponding to SDG 16: promote peaceful and inclusive societies for sustainable development, provide access to justice for all and build effective, accountable and inclusive institutions at all levels). In addition to the missing of indicator data regarding these two goals, the fact that the performance of goal 3 (indicators such as maternal mortality, multiple infectious disease incidence rate, traffic accident casualties, female adolescent fertility, family health expenditure, and provision of essential medicines and vaccines) was poor contributed as another major cause for the decreased score during the years 2005-2007. It is worth noting that the highest point in social SDGs is 6 points, while both Kazakhstan and Kyrgyzstan never scored more than 3 
points before 2010. Although they improved slightly and increased their scores above 3 points after 2010, due to insufficient measures to eradicate poverty, persistent weaker resilience, poor nutritional status, lack of sustainable agriculture, and poor performance in indicators related to ensuring healthy lifestyles (corresponding to SDG 3: ensure healthy lives and promote well-being for all at all ages), Kyrgyzstan again scored less than 3 points since 2016. The country's social sustainable development has been chronically poor and needs urgent improvement.

The best years in terms of social SDG performance were 2015 and 2012, scoring 3.63339 and 3.71344 for Kazakhstan and Kyrgyzstan, respectively; the worst year for both countries was 2001, scoring 1.23912 and 1.38303, respectively. In general, Kyrgyzstan performed better than Kazakhstan in terms of social SDGs during the years 2000-2012, whereas Kazakhstan performed better than Kyrgyzstan during the years 2013-2017.

\subsubsection{Environmental SDG Performance}

After we aggregated 16 of 17 SDGs (SDG 14 was excluded) into three dimensions (economy, society, and environment), the environmental SDGs contained SDG 6 (ensure availability and sustainable management of water and sanitation for all), SDG 7 (ensure access to affordable, reliable, sustainable and modern energy for all), SDG 11 (make cities and human settlements inclusive, safe, resilient and sustainable), SDG 12 (ensure sustainable consumption and production patterns), SDG 13 (take urgent action to combat climate change and its impacts), SDG 15 (protract, restore and promote sustainable use of terrestrial ecosystems, sustainably manage forests, combat desertification, and halt and reverse land degradation and halt biodiversity loss ).

In the evaluation of environmental SDG performance (Figure 2c), i.e., the total score of goals within this division, the score of Kazakhstan displayed a volatile fluctuation before embarking on an intense upward trend during the years 2000-2005 (increasing from 2.25234 to 3.56939). Its score fluctuated again before falling drastically to 1.04594 during the years 2005-2017 due to its insufficient capacity to withstand natural disasters (corresponding to SDG 11: make cities and human settlements inclusive, safe, resilient and sustainable, and SDG 13: take urgent action to combat climate change and its impacts) and the substantial missing of indicator data regarding the conservation \& restoration of ecosystems (corresponding to SDG 6: ensure availability and sustainable management of water and sanitation for all), as well as ensuring sustainable modern energy (corresponding to SDG 7: ensure access to affordable, reliable, sustainable and modern energy for all). Meanwhile, Kyrgyzstan's score presented a volatile upward trend (increasing from 2.54875 to 3.75262 ) until its score fell drastically to 1.04594 during the years 2015-2017 due to lack of protection and restoration of ecosystems, lack of sustainable management and efficient use of natural resources, inadequate capacity to withstand natural disasters (corresponding to SDG 6: ensure availability and sustainable management of water and sanitation for all, SDG 12: ensure sustainable consumption and production patterns, and SDG 13: take urgent action to combat climate change and its impacts), and the substantial missing of indicator data regarding ensuring sustainable modern energy (corresponding to SDG 7: ensure access to affordable, reliable, sustainable and modern energy for all) and reducing casualties and economic loss caused by disasters (corresponding to SDG 11: make cities and human settlements inclusive, safe, resilient and sustainable).

The best years in terms of environmental SDG performance were 2012 and 2011, scoring 3.76587 and 3.38941 for Kazakhstan and Kyrgyzstan, respectively; the worst year for both countries was 2017, scoring 1.72040 and 1.04594, respectively. In general, Kyrgyzstan performed better than Kazakhstan in terms of environmental SDGs during the years 2000-2004, whereas Kazakhstan performed better than Kyrgyzstan during the years 2004-2017.

\subsubsection{National Analysis of SDG Performance}

During the years 2000-2016, among the three dimensions of SDGs for Kyrgyzstan, the performance for both social and environmental goals showed an upward trend, growing by 0.67611 and 0.61646 , 
respectively, and ending at the same level of increase (Figure 2d). Nevertheless, during 2006-2016, the performance for environmental goals was more stable than that of social goals; economic goals, in comparison, underwent volatile fluctuation for those 17 years (ranging from 0.75 to 1.83). In addition, during 2016-2017, all three-dimensional goals presented downward trends, among which, the performance of environmental goals fell the most (decreasing by 2.11927), followed by social goals (decreasing by 1.39191). During 2000-2017, among all three divisional SDGs for Kyrgyzstan, the environmental SDGs performed the best overall, followed by the social SDGs, with the economic SDGs performing the worst among the three divisional SDGs.

During the years 2000-2016, the SDG scores for Kazakhstan in all dimensions presented an upward trend, among which the performance of social SDGs grew the most, increasing by 1.61703 , followed by economic SDGs (Figure 2e), whose score increased by 1.33987. During the years 2016-2017, the SDG scores in all three dimensions exhibited an evident downward trend, among which the environmental trend fell the most (decreasing by 1.73977), followed by social SDGs (decreasing by 0.86695). During 2000-2017, among the SDGs in all three dimensions for Kazakhstan, the environmental SDGs performed the best overall, followed by the economic SDGs, with the social SDGs performing the worst overall among the three divisional SDGs.

During the years 2000-2016, the total SDG scores for Kyrgyzstan and Kazakhstan, i.e., SDG overall performance, presented a progressive upward trend in fluctuation (Figure 3). However, the total score suddenly worsened during the years 2016-2017 due to the substantial missing of partial indicator data. It is worth noting that the SDG performance in Kyrgyzstan has been poor for almost 18 years. Its total SDG performance score was only higher than 8 points (half of the total scores of 16 SDGs involved in the assessment) in two years. For those 18 years, the best and worst years for Kyrgyzstan in terms of SDG performance were 2011 (8.25) and 2017 (3.82), respectively. For Kazakhstan, the best and worst years in terms of SDG performance were 2015 (10.27) and 2002 (4.76), respectively. In general, in terms of the overall SDG performance, Kyrgyzstan performed better than Kazakhstan during the years 2000-2005, while Kazakhstan performed better than Kyrgyzstan during the years 2005-2017.

\subsection{Analysis of Causes Affecting the Performance of Three Dimensions of SDGs in the Sample Area}

Table 3 shows the Chow test results regarding the breakpoints that appeared in the three dimensions of SDG performance trends for Kyrgyzstan and Kazakhstan during the years 2000-2017. It could be said told that, for those 18 years, there was no breakpoint in the economic trends of the SDG performance for both countries, while the environmental SDGs displayed a breakpoint in 2015. As for the social SDGs, only Kyrgyzstan had a breakpoint in 2011. Because the results of the Chow breakpoint test revealed the non-existence of breakpoints in the economic SDG performance trends, this paper can only attempt to unveil the possible causes for the sudden change of each divisional trend in SDG performance and conduct further analysis on all three divisional SDG performance over those 18 years. This assessment was based on the actual condition of both countries during the breakpoint years in combination with major events, disasters, relevant policies, and large-scale events. of the social and natural environments of the two countries occurring in the years of their respective breakpoints.

Table 3. Chow test for the breakpoint within the three divisional trends in SDG performance for Kyrgyzstan and Kazakhstan.

\begin{tabular}{ccccc}
\hline Country & Division & Breakpoint Year & F (2,14) & Prob. F (2,14) \\
\hline \multirow{3}{*}{ Kyrgyzstan } & Environment & 2015 & 14.4775 & 0.0004 \\
& Society & 2011 & 8.029292 & 0.0048 \\
& Economy & No Result & & \\
\hline \multirow{3}{*}{ Kazakhstan } & Environment & 2015 & 17.22005 & 0.0002 \\
& Society & No Result & & \\
& Economy & No Result & & \\
\hline
\end{tabular}




\subsubsection{Analysis of the Causes Affecting the Social SDG Performance in Kyrgyzstan}

Using 2011 as the breakpoint, the trend in social SDG performance in Kyrgyzstan can be divided into two parts (Figure 4), i.e., the upward trend during the years 2000-2011 and the downward trend during the years 2011-2017. Through the review and analysis of news and literature, this paper determined 7 types of major events as the main factors affecting the country's social SDG performance to assist with the analysis. For each major event, the scoring weight is determined through expert consultation. For the social events, the year in which the event occurred within 2000-2017 is scored as 1 point, and the year in which the event did not occur is scored as 0 points. For environmental events, the year in which the event occurred within 2000-2017 is scored as 0.5 points, and the year in which the event did not occur is scored as 0 points. Then, the scores of each year are summed to obtain the total social SDG-impacting factors of each year (Figure 4). These major events, disasters, and the times when they occurred are as follows: coups or revolution $(2005,2010)$, ethnic violence $(2010)$, real parliamentary system (2010-2017), presidential election $(2005,2009,2010,2011,2017)$, the outbreak of measles (2011, 2015, 2016, 2017), earthquakes of magnitude 6 or higher $(2005,2007,2008,2011,2015,2016)$, and harsh winter with low temperature and heavy snowfall $(2006,2010,2011,2012,2013)$. It can be seen from Figure 4 that, during 2000-2017, the first year with an outstanding score for factors impacting social sustainable development in Kyrgyzstan was 2005. After 2005, the social SDG performance quickly deteriorated and remained in a state of slow recovery for four years. After barely regaining its 2005 sustainable development level in 2010, Kyrgyzstan suffered the second outstanding year for social SDG impacting factors and it was the highest score in those 18 years. After that, the score for impacting factors in 2011 only trailed behind that of 2010. Those two years witnessed the steady accumulation of a series of social and political events and their subsequent impacts, as well as the frequent occurrence of natural disasters and environmental health issues, which rendered huge changes to the social and environmental circumstances affecting people's life. Moreover, the accumulated impacting factors score during 2015-2017 remained consistently high; therefore, the social SDG performance score fell quickly after 2012, making 2011 the breakpoint in the social SDG performance trend.

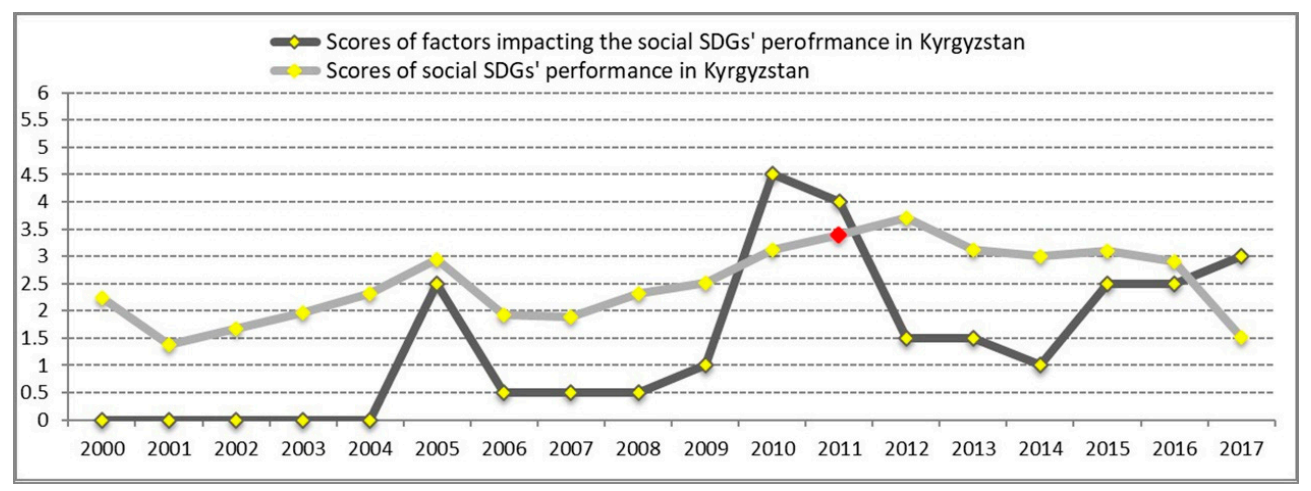

Figure 4. The scores for social SDG performance and factors impacting the social SDG performance in Kyrgyzstan from 2000 to 2017. Note: the red point is the breakpoint of the social SDG performance trend of Kyrgyzstan.

\subsubsection{Analysis of the Causes Affecting the Environmental SDG Performance in Kyrgyzstan}

Using 2015 as the breakpoint, the trend in environmental SDG performance in Kyrgyzstan can be divided into two parts (Figure 5), i.e., the fluctuating upward trend during the years 2000-2015 and the downward trend during the years 2015-2017. Through the review and analysis of news and literature, this paper determined 6 types of major disasters and crises as the main factors affecting the country's environmental SDG performance to assist with the analysis. For each major event, the year in which the event occurred within the years 2000-2017 was scored as 1 point, and the year in which the event did not occur was scored as 0 points; then, the sum of the scores for each year was obtained to get the total 
scores for the environmental SDG impacting factors for each year (Figure 5). These major events and the times when they occurred are as follows: serious avalanches that caused major casualties and property losses $(2004,2005,2010,2012,2014,2015,2017)$, landslides (2003, 2004, 2015, 2016, 2017), flooding (2004, $2005,2008,2012,2015)$, earthquakes of magnitude 6 or higher $(2005,2007,2008,2011,2015,2016)$, harsh winter with low temperature and heavy snowfall $(2006,2010,2011,2012,2013)$, and severe energy shortages $(2007,2008,2009,2013,2014,2015)$. It can be seen from Figure 5 that the accumulating scores for environmental SDG impacting factors in Kyrgyzstan remained in fluctuation during the years 2000-2014, especially, the accumulating scores for the impacting factors, which presented an upward trend during 2001-2004 while the environmental SDG performance continued to worsen during the same time period. In general, the SDG performance remained in stable fluctuation during 2000-2014. In 2015, which was the year with the highest impacting factor score, Kazakhstan suffered a series of natural disasters and energy crises that rendered lasting negative impact on the country's performance on goal $6,7,11,12$, and 13. As a result, its score for environmental SDG performance fell rapidly from 2015, making 2015 the breakpoint in the country's trend for environmental SDG performance.

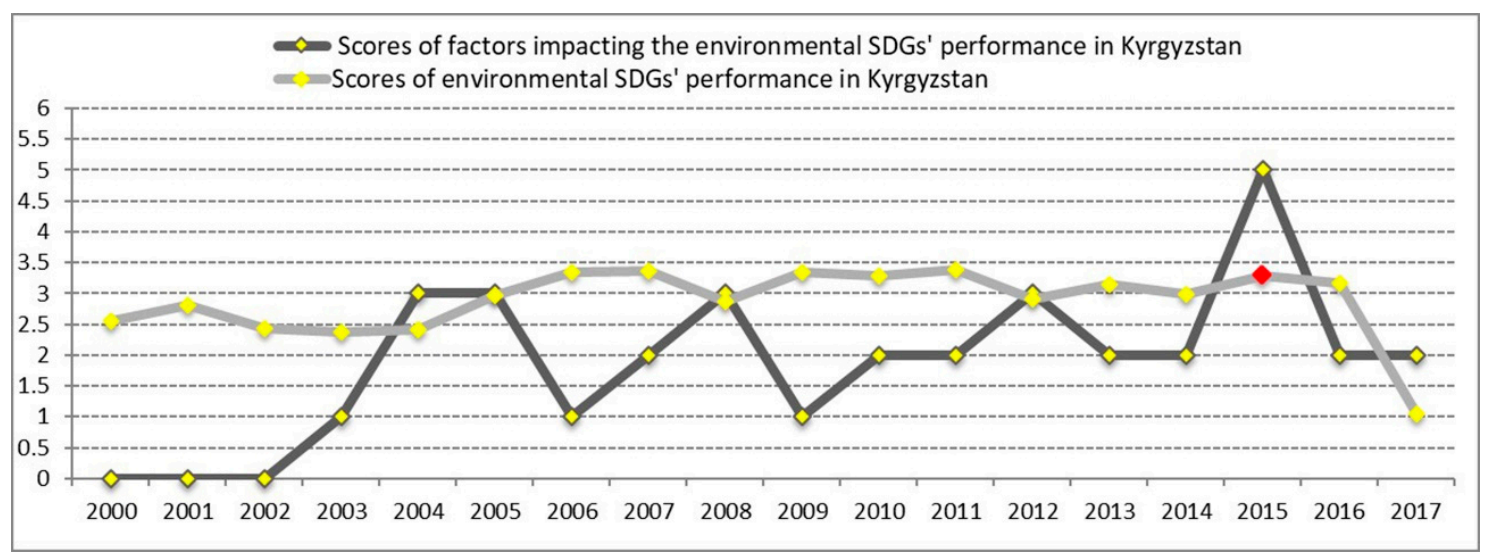

Figure 5. The scores of environmental SDG performance and factors impacting the environmental SDG performance in Kyrgyzstan from 2000 to 2017. Note: the red point is the breakpoint of the environmental SDG performance trend of Kyrgyzstan.

\subsubsection{Analysis of the Causes Affecting the Environmental SDG Performance in Kazakhstan}

Using 2015 as the breakpoint, the trend in environmental SDG performance in Kazakhstan can be divided into two parts (Figure 6), i.e., the fluctuating upward trend during the years 2000-2015 and the downward trend during the years 2015-2017. Through the review and analysis of news and literature, this paper determined 7 types of major disasters as the main factors affecting the country's environmental SDG performance to assist with the analysis. For each major event, the year in which the event occurred within 2000-2017 was scored as 1 point, and the year in which the event did not occur was scored as 0 points; then, the sum of the scores for each year was obtained to get the total scores for the environmental SDGs impacting factors for each year (Figure 6). These major disaster events and the times when they occurred are as follows: flooding causing major casualties and property losses $(2001,2005,2008,2010,2011,2012,2014,2015,2017)$, poisoning incidents such as syncope (2014, 2015), landslides causing major casualties and property losses $(2010,2015)$, earthquakes of magnitude 6 or higher $(2013,2017)$, thick smog with a stifling smell lasting for more than a week and causing residents to feel suffocation and weakness $(2012,2013,2014,2015,2016,2017)$, the death of many Dalmatian pelicans (2015), and the death of more than 200,000 saiga antelopes (2015). It can be seen from Figure 6 that the accumulating score for the environmental sustainable development impacting factors in Kazakhstan during 2000-2014 had been fluctuating within the low range, especially the accumulating score for impacting factors, which reached the lowest status during 2002-2004, and as a result, the environmental SDG performance recovered swiftly during 2004-2005. The highest score for 
impacting factors was in 2015, the year during which Kazakhstan suffered a series of serious natural environmental crises and sustained ecosystem damage, which rendered lasting negative impact on the completion of the country's goal 6,11,12,13, and 15. As a result, the environmental SDG performance score fell quickly, making 2015 the breakpoint in the country's environmental SDG performance trend.

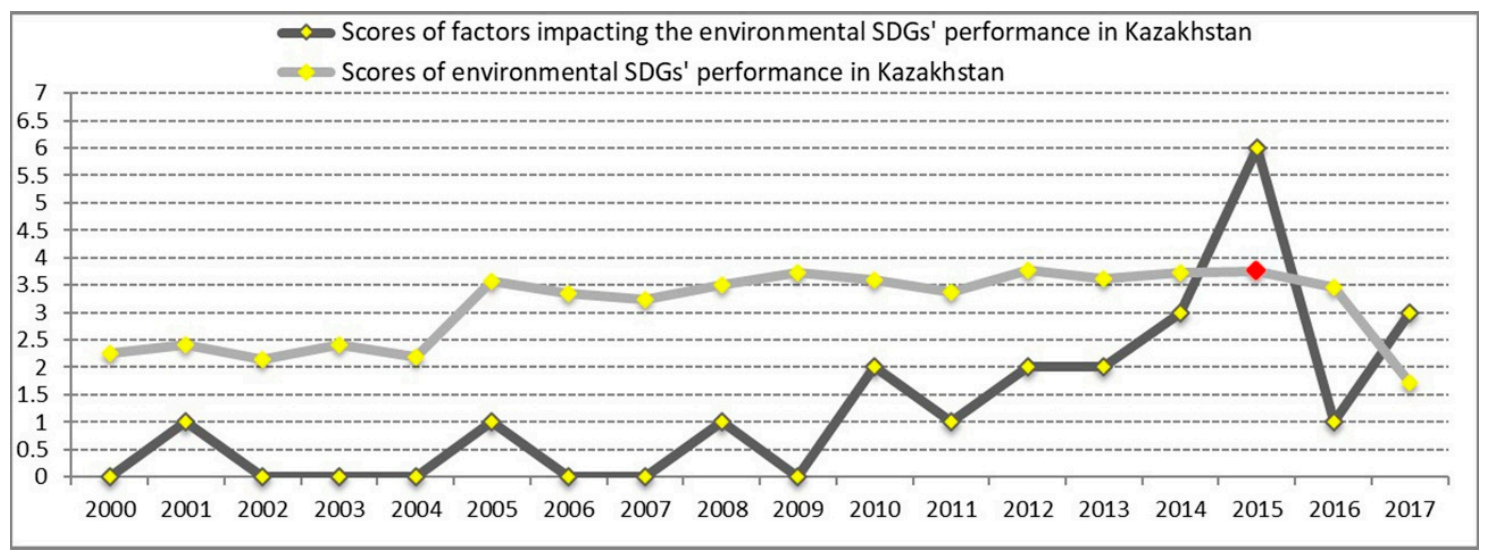

Figure 6. The scores of environmental SDG performance and factors impacting the environmental SDG performance in Kazakhstan from 2000 to 2017. Note: the red point is the breakpoint of the environmental SDG performance trend of Kazakhstan.

\subsection{The Advantages and Challenges of the Assessment Framework}

The assessment framework for SDG performance proposed in this paper has many advantages. First, due to the geographical differences of countries, they face different cooperation demands regarding proposals such as the BRI; thus, flexible indicators framework and assessment framework are particularly essential. Our indicator framework provided an entry point for the development of indicator selection. It is possible to continue to treat the indicators according to the indicator sets in order to divide them into different categories (such as gender, age and location.) based on research needs, enabling researchers to adjust the indicator framework based on the actual data obtainment of countries in different geographical areas and thus conduct more in-depth examination of the indicators. The researcher's analysis of the SDG performance of different regions within the same country can become a beneficial extension of the assessment framework proposed in this paper and can provide national policy-makers with more viable national information than an inter-country comparison. Second, based on the acquired indicator and focus area of the corresponding goal this paper categorized SDGs into three dimensions, i.e., society, economy, and environment. This method can realize the further clustering of indicators and lower the uncertainties that arise following the measurement and assessment within goal analysis that are caused by the substantial missing of partial indicator data, thus alleviating the burden on the national report while assisting researchers and policy-makers conduct macro-analysis and overall planning of national SDG performance. Third, we defined the maximum value of the time-series data for each indicator in the database and compared the value among different countries or regions. This was the best performance of the indicator so far and we used the maximum value to conduct normalization to demonstrate the degree of effort to achieve the best performance of the datasets within the time-series data that were less than the maximum value. On the one hand, this strengthens the connection of the internal trend among the indicator time-series data, but on the other hand, it emphasizes the comparison among different regions. Fourth, flexible weighting might encourage countries to perform easy goals and overlook goals that are equally important and demand further in-depth transformation. Therefore, for countries that use this assessment framework to analyze SDG performance, assigning equal weight to every SDG when calculating the SDG performance score could encourage equal focus on all goals, as well as inspire each country to concentrate on goals that are furthest from realization, and improve the fastest in terms of expected performance to 
improve future scores. Fifth, during the Chow test when there were many F statistic values greater than the critical value, this paper we selected only the maximum F statistic value as the breakpoint for analysis. Different researchers can conduct simultaneous analyses over a number of F statistic values greater than the critical value based on different demands, yielding a more accurate analysis of SDG performance trends for different countries. This method of breakpoint analysis, employing the breakpoint test while closely integrating it into the actual conditions in the area, is conducive to the scenario analysis, highlighting specific issues, policy assessment, and development of model direction selection among and within countries, which tests and supports the performance of SDGs. Sixth, many indicator-based assessments simply examine trend and progress and lack in-depth exploration of the comprehensive attributes of different countries' sustainable development and the inter-relationship among the encountered sustainable development. The formulation of a comprehensive methodological framework is a key component for this assessment, which could cluster intimately connected goals and indicators associated with its internal inter-relationship while simultaneously analyzing various special conditions of different regions [8]. The calculation and analysis of the assessment framework proposed in this paper are easily operable, increasing the chance for countries to adopt similar or edited versions and perform SDGs' progress assessment and analysis. In the future, countries and organizations around the world could adopt this method, for the long-term indicator-based SDGs assessment of both countries and regions.

However, there are still limitations and challenges that remain to be addressed in a future assessment framework. First, based on the collection of indicator data for the two countries assessed in this paper, it could be seen that there were still gaps in data collection between countries as well as the missing of time-series data. This could challenge the indicator selection and further restrict the follow-up assessment and analysis. For example, in the indicators regarding education (corresponding to SDG 4: ensure inclusive and equitable quality education and promote lifelong opportunities for all), water and sanitation (corresponding to SDG 6: ensure availability and sustainable management of water and sanitation for all), and implementation and global partnership (corresponding to SDG 17: strengthen the means of implementation and revitalize the global partnership for sustainable development), the gap in data collection was very evident. Furthermore, the missing of indicator data regarding ensuring sustainable modern energy (corresponding to SDG 7: ensure access to affordable, reliable, sustainable and modern energy for all), reducing inequality (corresponding to SDG 10: reduce inequality within and among countries), cities and settlements (corresponding to SDG 11: make cities and human settlements inclusive, safe, resilient and sustainable), consumption and production patterns (corresponding to SDG 12: ensure sustainable consumption and production patterns), and promoting peaceful societies and access to justice for all (corresponding to SDG 16: promote peaceful and inclusive societies for sustainable development, provide access to justice for all and build effective, accountable and inclusive institutions at all levels) was very serious. Also, the indicators regarding climate change (corresponding to SDG 13: take urgent action to combat climate change and its impacts) not only revealed a significant gap in data collection but also showed substantial data loss, an issue that demonstrated the challenges in data collection surrounding these aspects of Central Asia. As not every country, especially developing and underdeveloped countries, has access to continuous data, analytical or statistical methods would need to be used to fill the gap of missing data. Second, the SDG framework proposed by the UN is from a global perspective. Still, due to differences in terms of the sustainable development issues faced by different countries, each country has its own priorities in the acquisition of data in terms of its type and quality. Based on the UN SDG indicator framework, the monitoring and assessment worldwide or within countries in the same area would sometimes require the proposal of new substitute indicators for many countries. However, those substitute indicators with a strong subjective choice from the researchers might devalue the corresponding targets and SDGs. For the assessment of different regions within the same country, localizing processing and including more precise categorization of indicator data would be needed to formulate a national indicator system in line with the country's condition [63]. Third, for some research on the quantitative assessment 
of SDGs, several selected indicators might not well reflect and assess the SDGs and targets, which was a limitation of the indicators' framework. This was because, for a certain target, there were not enough corresponding indicators to reflect the target, and even if numbers of corresponding indicators were selected, those indicators might be only substitute indicators for the indicators proposed by the UN's SDGs. As mentioned before, those substitute indicators with a strong subjective choice from the researchers might devalue the targets. For example, indicator 37 (shown in Table 2) in the indicator framework of this paper is the proportion of total government spending on essential services (education), corresponding to target 1.a (ensure significant mobilization of resources from a variety of sources, including through enhanced development cooperation, in order to provide adequate and predictable means for developing countries, to implement programmes and policies to end poverty in all its dimensions) and SDG 1 (end poverty in all its forms everywhere). It can be seen that indicator 37 only monitored the government spending on essential educational services, which did not adequately and accurately reflect the purpose of ending poverty that the target 1.a and SDG 1 wanted to achieve. If two indicators (i.e., proportion of domestically generated resources allocated by the government directly to poverty reduction programmes; sum of total grants and non-debt-creating inflows directly allocated to poverty reduction programmes as a proportion of GDP) are added in accordance with the UN SDGs' indicators framework to assist indicator 37 in this paper for the assessment of the target 1.a and SDG 1, the final results will be more accurate. However, the sample area (Kazakhstan and Kyrgyzstan) of this paper did not have the relevant data of these two indicators; thus, only indicator 37 was used. Fourth, the universal 17 SDGs cover a wide range of content of sustainable development, such as all three major dimensions (economy, society, and environment) of sustainable development, as well as enablers such as institutional coherence, policy coherence, and accountability [48]. When fewer indicators are selected to assess SDGs, even if these indicators have certain comprehensiveness and representativeness, they may still result in a reduction or reorientation in the content of goals and targets. Therefore, to reduce this inaccuracy and incompleteness, based on the IAEG-SDGs' indicators framework, we selected plenty of indicators to assess SDGs. However, generalizing these diverse indicators we selected, lumping them together in a quantitative methodological framework and eventually giving them scores might devalue the indicators and seems complex and arbitrary. For the construction of a methodological framework including the selection of indicators and the classification and normalization of 17 SDGs, especially the selection of weighting methods and giving scores, using a direct rather than a complex method remains a critical challenge [64]. Among the increasingly complex assessments and analyses that are based on various models, more complex assessment methods lack practical significance for some underdeveloped countries. Therefore, a greater effort should be dedicated to guaranteeing that the assessment and analysis methods could be understood and used by the technical experts and researchers in different countries. However, for the assessment of SDGs that used a large number of indicators (around or over 100) such as the studies of Sachs et al. [30] and Eurostat [31], it can be said that the indicator framework of this paper was a further useful attempt, and the methodological framework of this paper was a compromise between the simpler quantitative assessment method (such as the combination of the min-max normalization and equal weights [65]) and the more complex quantitative assessment method (such as the combination of social network analysis and principal component analysis [66]; standard methods of the theory of choice and welfare under imposed quantities [67]). This kind of attempt and compromise addressed the problem of how to effectively measure, assess and compare the progress and trends of SDGs in different countries.

\section{Conclusions}

Based on past case studies, this paper constructed a novel analysis framework for the assessment of SDGs including methods such as benchmarking, normalization, and employment of the Chow Test to uncover breakpoints within SDG performance trends as well as further analysis of SDG performance for the clustered 17 SDGs in the three dimensions of economy, society, and environment. This paper also used two typical Central Asian countries, Kazakhstan and Kyrgyzstan, as the sample area to 
test whether this methodological framework could realize the comprehensive assessment over the country's long-term performance and trends for SDGs.

For the sample area, this assessment finally used 209 indicators and indicator sets including 429 specific indicators corresponding to 16 SDGs (except SDG 14 from 17 SDGs) in three dimensions, i.e., economy, society, and environment. Specifically, economic dimension included 141 specific indicators corresponding to SDG 8 (promote sustained, inclusive and sustainable economic growth, full and productive employment and decent work for all), SDG 9 (build resilient infrastructure, promote inclusive and sustainable industrialization and foster innovation), SDG 10 (reduce inequality within and among countries) and SDG 17 (strengthen the means of implementation and revitalize the global partnership for sustainable development); the social dimension included 220 specific indicators corresponding to SDG 1 (end poverty in all its forms everywhere), SDG 2 (end hunger, achieve food security and improved nutrition and promote sustainable agriculture), SDG 3 (ensure healthy lives and promote well-being for all at all ages), SDG 4 (ensure inclusive and equitable quality education and promote lifelong opportunities for all), SDG 5 (achieve gender equality and empower all women and girls) and SDG 16 (promote peaceful and inclusive societies for sustainable development, provide access to justice for all and build effective, accountable and inclusive institutions at all levels); the environmental dimension included 220 specific indicators corresponding to SDG 6 (ensure availability and sustainable management of water and sanitation for all), SDG 7 (ensure access to affordable, reliable, sustainable and modern energy for all), SDG 11 (make cities and human settlements inclusive, safe, resilient and sustainable), SDG 12 (ensure sustainable consumption and production patterns), SDG 13 (take urgent action to combat climate change and its impacts) and SDG 15 (protract, restore and promote sustainable use of terrestrial ecosystems, sustainably manage forests, combat desertification, and halt and reverse land degradation and halt biodiversity loss). The assessment revealed that, in terms of economic SDG performance, Kyrgyzstan's was the worst performance among the three divisional SDGs for the two countries, and was in urgent need of improvement. Furthermore, in terms of social SDG performance, it was evident that Kazakhstan performed better than Kyrgyzstan after 2013. During the years 2010-2011, a series of major incidents occurred in Kyrgyzstan that rendered its social sustainable development severely affected. Our findings indicated that governments should pay particular attention to strengthening their country's capability to withstand various types of disasters for vulnerable groups and guarantee healthy lifestyles as well as quality education. Moreover, in terms of the performance of environmental SDGs, the overall performance of the two countries' environmental sustainable development was relatively good. However, after 2015, both countries suffered a series of major disaster incidents that resulted in natural resources and ecological environmental crises that left a lasting impact on their environmental sustainable development. Namely, they were unable to meet the requirements of proactive promotion of new policies, strengthening of disaster monitoring and alert, improvement of the regional disaster-preparation system, and the avoidance of the accumulation of natural environmental issues. In terms of the overall SDG performance, it could be said that for Central Asia as a whole, the SDG performance was not very optimistic and required that greater effort be devoted to the gathering of different types of indicator data to solve the issue of data loss.

Testing of the assessment framework using the sample area revealed that this paper adjusted the indicator system according to the actual data gathering of different countries, clustered goals and indicators closely related to regional sustainable development, emphasized its internal interconnection, and simultaneously analyzed different special situations of different regions before formulating a comprehensive methodological assessment framework. The calculation and analysis of this paper's assessment framework are easily operable for other countries. Therefore, future research will focus on extending this study's sample area to all countries under the BRI by using the methodological framework of this paper. We believe this assessment framework can be successfully employed for long-term SDGs assessment in those countries. Our assessment framework can help countries to understand their advantages and disadvantages in the development of economy, society and environment from a quantitative point of view, upgrade and transform the vulnerable industries, achieve the overall 
layout of industrial structure from a global perspective, and expand the international markets. Finally, we expect our assessments can assist policy-makers to learn the dynamic interconnections between countries and existing challenges and opportunities, evaluate a development model, and formulate sustainable development policies.

Supplementary Materials: The following are available online at http://www.mdpi.com/2071-1050/11/13/3504/s1, Table S1: original data of Kyrgyzstan SDG-related indicators. Table S2: original data of Kazakhstan SDG-related indicators. Table S3: indicator framework used for the SDGs assessment.

Author Contributions: Conceptualization, Y.H. and H.L.; Methodology, H.L.; Validation, Y.H. and H.L.; Formal Analysis, Y.H.; Investigation, Y.H.; Resources, Y.H.; Data Curation, Y.H.; Writing-Original Draft Preparation, Y.H.; Writing-Review and Editing, H.L. and T.L.; Visualization, Y.H.; Supervision, H.L. and T.L.; Project Administration, H.L. and T.L.; Funding Acquisition, T.L.

Funding: This research was funded by the Strategic Priority Research Program A of the Chinese Academy of Sciences, No. XDA20010301.

Acknowledgments: The authors would like to acknowledge and thank the support of China Scholarship Council, and Institute of Geographic Sciences and Natural Resources Research, Chinese Academy of Sciences.

Conflicts of Interest: The authors declare no conflict of interest.

\section{References}

1. Böhringer, C.; Jochem, P.E.P. Measuring the immeasurable-A survey of sustainability indices. Ecol. Econ. 2007, 63, 1-8. [CrossRef]

2. Mayer, A.L. Strengths and weaknesses of common sustainability indices for multidimensional systems. Environ. Int. 2008, 34, 277-291. [CrossRef] [PubMed]

3. Singh, R.K.; Murty, H.R.; Gupta, S.K.; Dikshit, A.K. An overview of sustainability assessment methodologies. Ecol. Indic. 2009, 9, 189-212. [CrossRef]

4. Dahl, A.L. Achievements and gaps in indicators for sustainability. Ecol. Indic. 2012, 17, 14-19. [CrossRef]

5. Mori, K.; Christodoulou, A. Review of sustainability indices and indicators: Towards a new City Sustainability Index (CSI). Environ. Impact Asses. 2012, 32, 94-106. [CrossRef]

6. Dasgupta, P.; Duraiappah, A.; Managi, S.; Barbier, E.; Collins, R.; Fraumeni, B.; Gundimeda, H.; Liu, G.; Mumford, K.J. How to measure sustainable progress. Science 2015, 350, 748. [CrossRef] [PubMed]

7. United Nations (UN). The Sustainable Development Goals Report 2018; United Nations: New York, NY, USA, 2018.

8. Allen, C.; Nejdawi, R.; El-Baba, J.; Hamati, K.; Metternict, G.; Weidmann, T. Indicator-based assessments of progress towards the sustainable development goals (SDGs): A case study of the Arab region. Sustain. Sci. 2017, 12, 975-989. [CrossRef]

9. Sustainable Development Solutions Network. Indicators and a Monitoring Framework for the Sustainable Development Goals; Sustainable Development Solutions Network: New York, NY, USA, 2015.

10. Eurostat. Getting Messages across Using Indicators: A Handbook Based on Experience from Assessing Sustainable Development Indicators; Eurostat: Luxembourg, 2014.

11. Wu, C.L.; Wang, Q. Comparative study on evaluation of resource and environment carrying capacity based on two different models. J. Subtrop. Resour. Environ. 2018, 13, 59-65. [CrossRef]

12. Zhang, Y. Statistical analysis on sustainable urban development capacity of Liu'an city, Anhui Province. J. Heibei North Univ. 2013, 29, 50-57. [CrossRef]

13. Guo, C.Z.; Peng, Z.Y.; Ding, J.Q. Construction of the indexes of DEA used in comprehensive evaluation of sustainable development. China Popul. Resour. Environ. 2016, 26, 9-17. [CrossRef]

14. Gable, S.; Lofgren, H.; Rodarte, I.O. Trajectories for Sustainable Development Goals: Framework and Country Application; World Bank: Washington, DC, USA, 2015.

15. Kroll, C. Sustainable Development Goals: Are the Rich Countries Ready; Bertelsmann Stiftung: Gutersloh, Germany, 2015.

16. Nejdawi, R.; Braham, M.; El-Baba, J.; Razzaz, S.; Allen, C.; Fadil, F.A.; Ismail, K.A.; Baydas, L.; Cherfane, C.C.; el-Andaloussi, H.; et al. Arab Sustainable Development Report; United Nations Economics and Social Commission for Western Asia and United Nations Environment Programme: Beirut, Lebanon, 2015. 
17. Costanza, R.; Daly, L.; Fioramonti, L.; Giovannini, E.; Kubiszewski, I.; Mortensen, L.F.; Pickett, K.E.; Ragnarsdottir, K.V.; Vogli, R.D.; Wilkinson, R. Modelling and measuring sustainable wellbeing in connection with the UN sustainable development goals. Ecol. Econ. 2016, 130, 350-355. [CrossRef]

18. Lim, S.S.; Fullman, N.; Murray, C.J.L.; Kutz, M.J.; Goldberg, E.M.; Pigott, D.M.; Allen, K.; Bhutta, Z.A.; Dandona, L.; Forouzanfar, M.H.; et al. Measuring the health-related sustainable development goals in 188 countries: A baseline analysis from the global burden of disease study 2015. Lancet 2016, 388, 1813-1850. [CrossRef]

19. Sachs, J.; Schmidt-Traub, G.; Kroll, C.; Durand-Delacre, D.; Teksoz, K. SDG Index and Dashboards-Global Report; Bertelsmann Stiftung and Sustainable Development Solutions Network: New York, NY, USA, 2016.

20. United Nations (UN). The Sustainable Development Goals Report 2016; United Nations: New York, NY, USA, 2016.

21. Clark, C.M.A.; Kavanagh, C. Sustainable Progress Index 2017; Social Justice Ireland: Dublin, Ireland, 2017.

22. Fullman, N.; Barber, R.M.; Abajobir, A.A.; Abate, K.H.; Abbafati, C.; Abbas, K.M.; Abd-Allah, F.; Abdulle, A.M.; Abera, K.M.; Aboyans, V.; et al. Measuring progress and projecting attainment on the basis of past trends of the health-related sustainable development goals in 188 countries: An analysis from the global burden of disease study 2016. Lancet 2017, 390, 1423-1459. [CrossRef]

23. Organisation for Economic Cooperation and Development. Measuring Distance to the SDGs Targets: An Assessment of Where OECD Countries Stand; Organisation for Economic Cooperation and Development: Paris, France, 2017.

24. Reyers, B.; Stafford-Smith, M.; Erb, K.-H.; Scholes, R.J.; Selomane, O. Essential variables help to focus sustainable development goals monitoring. Curr. Opin. Environ. Sustain. 2017, 26, 97-105. [CrossRef]

25. Sachs, J.; Schmidt-Traub, G.; Kroll, C.; Durand-Delacre, D.; Teksoz, K. SDG Index and Dashboards Report 2017; Bertelsmann Stiftung and Sustainable Development Solutions Network: New York, NY, USA, 2017.

26. United Nations (UN). The Sustainable Development Goals Report 2017; United Nations: New York, NY, USA, 2017.

27. Campagnolo, L.; Eboli, F.; Farnia, L.; Carraro, C. Supporting the UN SDGs transition: Methodology for sustainability assessment and current worldwide ranking. Econ. Open-Access Open-Assess. E-J. 2018, 12, 1-31. [CrossRef]

28. Clark, C.M.A.; Kavanagh, C.; Lenihan, N. Ireland vs EU28: Monitoring Ireland's Performance towards Achieving the SDGs; Social Justice Ireland: Dublin, Ireland, 2018.

29. Clark, C.M.A.; Kavanagh, C.; Lenihan, N. Measuring Progress: Economy, Society and Environment in Ireland; Social Justice Ireland: Dublin, Ireland, 2018.

30. Sachs, J.; Schmidt-Traub, G.; Kroll, C.; Lafortune, G.; Fuller, G. SDG Index and Dashboards Report 2018; Bertelsmann Stiftung and Sustainable Development Solutions Network: New York, NY, USA, 2018.

31. Eurostat. Sustainable Development in the European Union: 2017 Monitoring Report on Progress towards the SDGs in an EU Context; Eurostat: Luxembourg, 2017.

32. Janoušková, S.; Hák, T.; Moldan, B. Global SDGs assessments: Helping or confusing indicators? Sustainability 2018, 10, 1540. [CrossRef]

33. United Nations. Global Indicator Framework for the Sustainable Development Goals and Targets of the 2030 Agenda for Sustainable Development; United Nations: New York, NY, USA, 2018.

34. El-Maghrabi, M.H.; Gable, S.; Rodarte, I.O.; Verbeek, J. Sustainable Development Goals Diagnostics: An Application of Network Theory and Complexity Measures to Set Country Priorities; World Bank: Washington, DC, USA, 2018.

35. Hu, J.; Zhang, W.Q.; Xing, F.; Geng, H.Q. Research on the measurement and evaluation of national economic and social development from the perspective of the belt and road initiative. Stat. Inf. Forum 2018, 33, $43-53$.

36. Hou, L.M. A geopolitical economic analysis on the initiative of "the belt and road". J. Xi'an Univ. Financ. Econ. 2017, 30, 85-89. [CrossRef]

37. United Nations Department of Economic and Social Affairs. World Population Prospects: The 2017 Revision. 2017. Available online: https://population.un:wpp/DataQuery/ (accessed on 31 December 2018).

38. World Bank. Kazakhstan Partnership Programme Snapshot. 2017. Available online: https://www.worldbank. org (accessed on 31 December 2018).

39. Central Intelligence Agency. The World Fact Book. 2018. Available online: https://www.cia.gov/library/ publications/the-world-factbook/geos/kz.html (accessed on 30 December 2018). 
40. International Monetary Fund. Report for Kazakhstan. 2018. Available online: https://www.imf: external/pubs/ft/weo/2018/02/weodata/weorept.aspx?pr.x=32\&pr.y=5\&sy=2019\&ey=2019\&scsm=1\&ssd= $1 \&$ sort $=$ country $\& \mathrm{ds}=. \& \mathrm{br}=1 \& \mathrm{c}=916 \& \mathrm{~s}=\mathrm{NGDPD} \% 2 \mathrm{CPPPGDP} \% 2 \mathrm{CNGDPDPC} \% 2 \mathrm{CPPPPC} \& \mathrm{grp}=0 \& \mathrm{a}$ (accessed on 31 December 2018).

41. Sidaway, J.D.; Woon, C.Y. Chinese narratives on "one belt, one road" in geopolitical and imperial contexts. Prof. Geogr. 2017, 69, 591-603. [CrossRef]

42. Wolff, C.; Plessen, B.; Dudashvilli, A.; Breitenbach, S.F.M. Precipitation evolution of central Asia during the last 5000 years. Holocene 2017, 27, 142-154. [CrossRef]

43. Yuldashev, F.; Sahin, B. The political economy of mineral resource use: The case of Kyrgyzstan. Resour. Policy 2016, 49, 266-272. [CrossRef]

44. International Monetary Fund. Report for Kyrgyzstan. 2018. Available online: https://www.imf: external/pubs/ft/weo/2018/02/weodata/weorept.aspx?sy=2016\&ey=2022\&scsm=1\&ssd=1\&sort=country\& $\mathrm{ds}=. \& \mathrm{br}=1 \& \mathrm{c}=917 \& \mathrm{~s}=$ PPPGDP\%2CPPPPC\&grp=0\&a=\&pr.x=17\&pr.y=18 (accessed on 31 December 2018).

45. United Nations (UN). Transforming Our World: The 2030 Agenda for Sustainable Development; United Nations: New York, NY, USA, 2015.

46. Inter-Agency Expert Group on Sustainable Development Goals Indicators (IAEG-SDGs). A World that Counts: Mobilising the Data Revolution for Sustainable Development; United Nations: New York, NY, USA, 2014.

47. United Nations (UN). Report of the Inter-Agency and Expert Group on Sustainable Development Goal Indicators; United Nations: New York, NY, USA, 2016.

48. Ordaz, E. The SDGs indicators: A challenging task for the international statistical community. Glob. Policy 2019, 10, 141-143. [CrossRef]

49. MacFeely, S. The big (data) bang: Opportunities and challenges for compiling SDG indicators. Glob. Policy 2019, 10, 121-133. [CrossRef]

50. Xue, L.; Weng, L.F. The policy opportunities and challenges in China's implementation of 2030 sustainable development goals. Chin. Soft Sci. 2017, 1, 1-12.

51. United Nations (UN). The Global SDG Indicators Database; United Nations: New York, NY, USA, 2016; Available online: https://unstats.un:sdgs/indicators/database/ (accessed on 27 September 2018).

52. Inter-Agency and Expert Group on Sustainable Development Goals Indicators (IAEG-SDGs). Tier Classification for Global SDG Indicators. Available online: https://unstats.un:sdgs/iaeg-sdgs/ (accessed on 15 June 2019).

53. Pollesch, N.L.; Dale, V.H. Normalization in sustainability assessment: Methods and implications. Ecol. Econ. 2016, 130, 195-208. [CrossRef]

54. Maxim, A. Sustainability assessment of electricity generation technologies using weighted multi-criteria decision analysis. Energy Policy 2014, 65, 284-297. [CrossRef]

55. Krajnc, D.; Glavič, P. A model for integrated assessment of sustainable development. Resour. Conserv. Recycl. 2005, 43, 189-208. [CrossRef]

56. Dias, L.C.; Domingues, A.R. On multi-criteria sustainability assessment: Spider-Gram surface and dependence biases. Appl. Energy 2014, 113, 159-163. [CrossRef]

57. Booysen, F. An overview and evaluation of composite indices of development. Soc. Indic. Res. 2002, 59, 115-151. [CrossRef]

58. França, V.H.; Confalonieri, U.E.C. Local communities, health and the sustainable development goals: The case of Ribeirão das Neves, Brazil. Cad. Metrópole 2016, 18, 365-375. [CrossRef]

59. Spaiser, V.; Ranganathan, S.; Swain, R.B.; Sumpter, D.J.T. The sustainable development oxymoron: Quantifying and modeling the incompatibility of sustainable development goals. Int. J. Sustain. Dev. World Ecol. 2017, 24, 457-470. [CrossRef]

60. Lim, M.M.L.; Jørgensen, P.S.; Wyborn, C.A. Reframing the sustainable development goals to achieve sustainable development in the Anthropocene-A systems approach. Ecol. Soc. 2018, 23, 22. [CrossRef]

61. Chow, G.C. Tests of equality between sets of coefficients in two linear regressions. Econometrica 1960, 28, 591-605. [CrossRef]

62. Yang, H.W.; Wang, D.H. Quandt-Andrews method for linear regression model parameters stability test. J. Appl. Stat. Manag. 2013, 32, 823-829. [CrossRef] 
63. Stafford-Smith, M.; Griggs, D.; Gaffney, O.; Ullah, F.; Reyers, B.; Kanie, N.; Stigson, B.; Shrivastava, P.; Leach, M.; O'Connell, D. Integration: The key to implementing the sustainable development goals. Sustain. Sci. 2017, 12, 911-919. [CrossRef] [PubMed]

64. Hogan, D.R.; Stevens, G.A.; Hosseinpoor, A.R.; Boerma, T. Monitoring universal health coverage within the sustainable development goals: Development and baseline data for an index of essential health services. Lancet Glob. Health 2017, 6, 152-168. [CrossRef]

65. Zhu, J.; Sun, X.Z.; He, Z. Research on China's sustainable development evaluation indicators in the framework of SDGs. China Popul. Resour. Environ. 2018, 28, 9-18. [CrossRef]

66. Zhou, X.; Feng, T.T.; Xu, M. Determination of strategic targets and core indicators for sustainable development goals (SDGs) integration in China based on SDG interlinkages analysis and statistical method. Bull. Chin. Acad. Sci. 2018, 33, 20-29. [CrossRef]

67. Barbier, E.B.; Burgess, J.C. The sustainable development goals and the systems approach to sustainability. Econ. Open-Access Open-Assess. E-J. 2017, 11, 1-22. [CrossRef]

(C) 2019 by the authors. Licensee MDPI, Basel, Switzerland. This article is an open access article distributed under the terms and conditions of the Creative Commons Attribution (CC BY) license (http://creativecommons.org/licenses/by/4.0/). 